OPEN ACCESS

Edited by:

Cornelis F.M. Sier.

Leiden University, Netherlands

Reviewed by:

Ruchi Bansal,

University of Twente, Netherlands Maarten Fokke Biilsma,

Amsterdam University Medical Center

(UMC), Netherlands

*Correspondence:

Alexandr V. Bazhin

alexandr.bazhin@med.uni-

muenchen.de

${ }^{t}$ These authors have contributed equally to this work

Specialty section: This article was submitted to Gastrointestinal Cancers, a section of the journal

Frontiers in Oncology

Received: 27 October 2020 Accepted: 27 November 2020

Published: 14 January 2021

Citation:

Wu Y, Zhang C, Jiang K, Werner J, Bazhin AV and D'Haese JG (2021)

The Role of Stellate Cells in

Pancreatic Ductal Adenocarcinoma:

Targeting Perspectives.

Front. Oncol. 10:621937.

doi: 10.3389/fonc.2020.621937

\section{The Role of Stellate Cells in Pancreatic Ductal Adenocarcinoma: Targeting Perspectives}

\author{
Yang $\mathrm{Wu}^{1 \dagger}$, Chun Zhang ${ }^{1 \dagger}$, Kuirong Jiang ${ }^{2}$, Jens Werner ${ }^{1,3}$, Alexandr V. Bazhin ${ }^{1,3 *}$ \\ and Jan G. D'Haese ${ }^{1 \dagger}$ \\ ${ }^{1}$ Department of General, Visceral, and Transplant Surgery, Ludwig-Maximilians-University Munich, Munich, Germany, \\ 2 Pancreas Center and Pancreas Institute, Nanjing Medical University, Nanjing, China, ${ }^{3}$ German Cancer Consortium (DKTK), \\ Partner Site Munich, Munich, Germany
}

Pancreatic ductal adenocarcinoma (PDAC) is a gastrointestinal malignancy with a dismal clinical outcome. Accumulating evidence suggests that activated pancreatic stellate cells (PSCs), the major producers of extracellular matrix (ECM), drive the severe stromal/ desmoplastic reaction in PDAC. Furthermore, the crosstalk among PSCs, pancreatic cancer cells (PCCs) as well as other stroma cells can establish a growth-supportive tumor microenvironment (TME) of PDAC, thereby enhancing tumor growth, metastasis, and chemoresistance via various pathways. Recently, targeting stroma has emerged as a promising strategy for PDAC therapy, and several novel strategies have been proposed. The aim of our study is to give a profound review of the role of PSCs in PDAC progression and recent advances in stroma-targeting strategies.

Keywords: pancreatic stellate cells, pancreatic ductal adenocarcinoma, tumor microenvironment, stromatargeting strategy, tumor therapy

\section{INTRODUCTION}

About one century after Karl von Kupffer discovered hepatic stellate cells (HSCs) in 1876, similar star-shaped vitamin A-storing cells (later known as PSCs) in the pancreas were first observed by Wateri et al. in 1982 (1). However, scientists cannot study these cells in both health and pathology until two landmark articles outlined the in vitro isolation and culture methods of PSCs in 1998 (2, 3). From then on, emerging studies focused on this new field, and PSCs are now well known as the main cause of the stromal/desmoplastic reaction which is the typical feature of PDAC and chronic pancreatitis (CP) (4-7).

As a malignancy with poor clinical outcomes (8), PDAC develops when pancreatic cells grow out of control and acquire the ability to invade other organs of the body $(9,10)$. The cancer-centric therapeutics have shown dismal efficacy in eradicating PDAC, since the severe fibrogenic stromal reaction plays both tumor-supporting and -restraining roles in tumor progression and chemotherapy resistance $(4,11-13)$. As the most abundant stromal cells and major ECM producers, activated PSCs (aPSCs) are known as the critical participants in the stromal/ desmoplastic reaction which characterizes PDAC (4). In addition, the dynamic interaction among PSCs, PCCs and other stroma cells create an extremely complex microenvironment which plays a pivotal role in PDAC progression $(14,15)$. Therefore, PSCs have received great 
attention, and targeting PSCs has emerged as a hopeful strategy for PDAC therapy recently $(12,14)$. In this article, we will review the role of PSCs in the development of PDAC and novel therapeutic targets proposed by PSC-related studies.

\section{PSCS IN THE PDAC}

\section{Different Phenotypes of PSCs}

PSCs can present in two different phenotypes: the quiescent and activated types. In health, PSCs are located in the peri-acinar or interlobular regions of normal pancreas and show a quiescent status (qPSCs), with many perinuclear droplets and a low capacity to produce $\operatorname{ECM}(2,3)$. qPSCs comprise around $4 \%$ of the local cells in pancreas (15) and participate in the vitamin A storage, immunity, normal exocrine and endocrine secretion, and the maintenance of normal architecture of the pancreas (16). qPSCs could express desmin, glial fibrillary acidic protein (GFAP), vimentin, nestin, nerve growth factor, and neural cell adhesion molecule (14). Recently, Nielsen et al. indicated that cytoglobin and adipophilin were markers of qPSCs in the normal human pancreas (17).

Numerous mechanisms are involved in the activation process of qPSCs, including risk factors (e.g. smoking, alcohol intake,
$\mathrm{CP}$ ), environmental stress (e.g. oxidative stress and hypoxia), elevated secretion of factors and signaling pathways (18) (Figure 1). During the development of diseases like PDAC or $\mathrm{CP}$, qPSCs can transform into a myofibroblast-like phenotype $(19,20)$. aPSCs show a positive immunostaining of $\alpha$-smooth muscle actin ( $\alpha \mathrm{SMA})$, loss of intracellular lipid droplets, enhanced release of numerous molecules, elevated migration and proliferation ability, high ECM protein production [e.g. collagens, laminin, hyaluronic acid (HA) and fibronectin] as well as the imbalanced secretion of tissue inhibitors of metalloproteinases (TIMPs) and matrix metalloproteases (MMPs), thus profoundly remodeling $\operatorname{TME}(19,20)$. Table 1 listed the features of qPSCs and aPSCs.

\section{Origins of PSCs}

The origins of stellate cells are still under investigation. The mesoderm (21-23), neuroectoderm $(24,25)$ and endoderm $(26$, 27) were suggested to be the origins of stellate cells. The exact source of PSCs is unclear, since they express a range of neuroectodermal and mesenchymal markers (28). Two in vivo studies have suggested that bone marrow is a major source of PSCs $(29,30)$. Recently, Ino et al. found that C-C chemokine receptor type $2(\mathrm{CCR} 2)^{+}$monocytes could infiltrate the pancreas

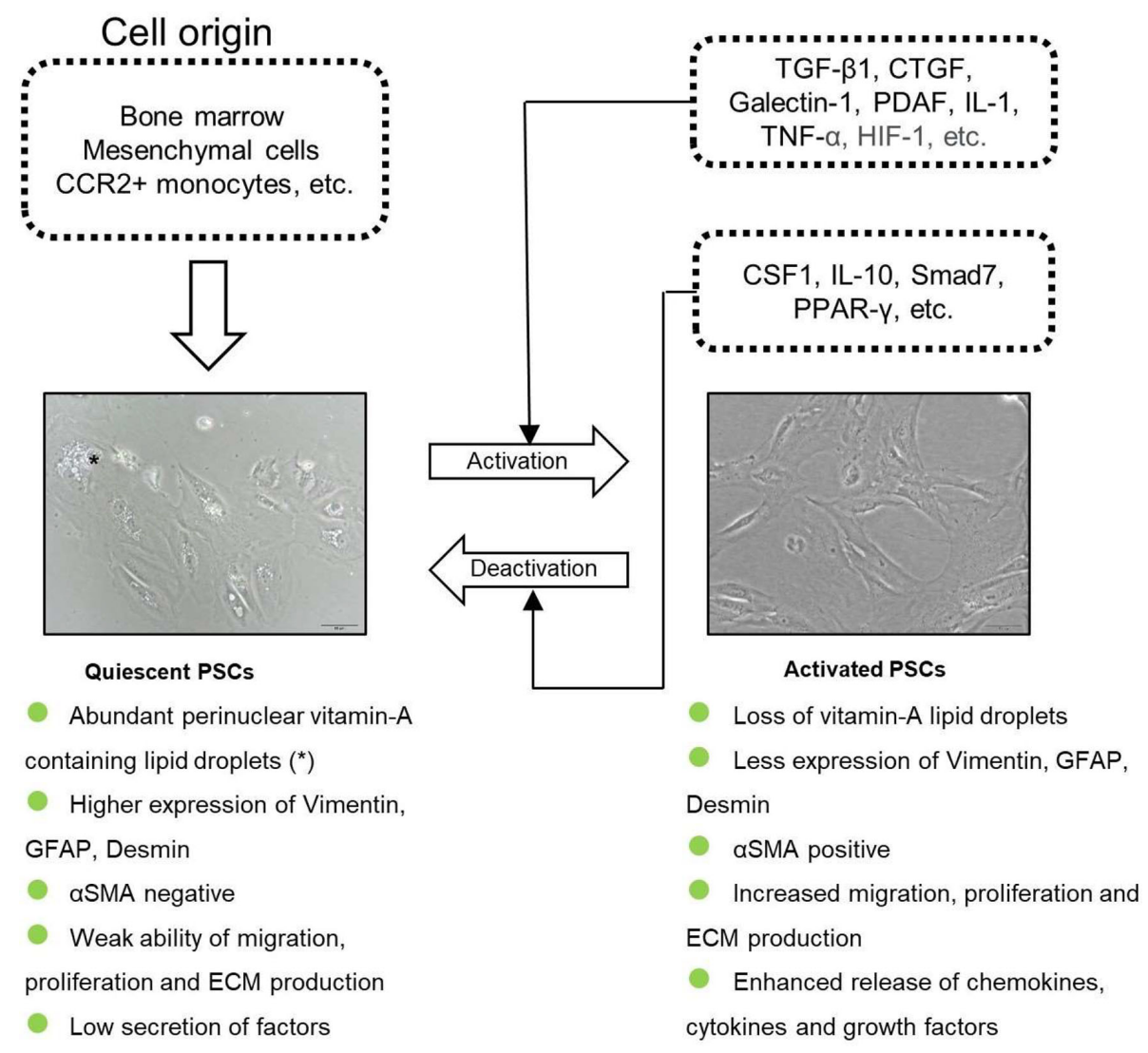

FIGURE 1 | The origin and the activation of PSCs. PSCs are derived from bone marrow, mesenchymal cells and CCR2+ monocytes. qPSCs get activated by several cytokines and transformed into a myofibroblast-phenotype. 
TABLE 1 | The features of qPSCs and aPSCs.

\begin{tabular}{|c|c|c|c|}
\hline Features & qPSCs & aPSCs & Pathways in the activation \\
\hline Vitamin A-rich lipid droplets & Positive & Negative & MAPK (ERK, JNK, p38); Rho/ROCK; NF- $\kappa$ B; PPAR- $\gamma$, \\
\hline$\alpha \mathrm{SMA}$ & Negative & Positive & PI3K/Akt; JAK/STAT; Smads; Hedgehog \\
\hline Vimentin, GFAP, Desmin & More & Less & \\
\hline Migration, Proliferation, ECM release abilities & Weak & Strong & \\
\hline MMPs and TIMPs' secretion & Normal secretion & $\begin{array}{l}\text { Unbalanced secretion of MMPs } \\
\text { and TIMPs }\end{array}$ & \\
\hline Cytokines, chemokines, growth factors' production & Low & High & \\
\hline
\end{tabular}

via the monocyte chemoattractant protein-1 (MCP-1)/CCR2 pathway and differentiate into PSCs (31). However, research on the origins of PSCs is still lacking. Given that PSCs and HSCs exhibited significant similarities through morphological, functional, and gene expression studies $(12,32)$, research on HSCs will be of reference significance. Cell lineage tracing research demonstrated that HSCs originated from mesenchymal cells and evolved from the mesoderm $(23,33)$. PSCs might also derive from the neural lineage since they show a positive expression of neuroectodermal markers like GFAP and nerve growth factor (NGF). Similar tracing studies are urgently needed to determine the exact origins of PSCs. Since PSCs are also heterogeneous, a single origin will not derive the entire population but may contribute to the total cell pool what we call PSCs. In-depth understanding of the different origins of PSCs will help us discover their essence and facilitate the development of clinical treatment for PDAC.

\section{PSCs Heterogeneity and Biomarkers}

The heterogeneity of PDAC and PSCs has been widely discussed and studied recently $(28,34)$. Several distinct cell subgroups with different biomarkers contribute to the heterogeneity of PSCs. Disparate PSCs subsets have multiple functions in PDAC and act as the promoter or preventer in PDAC development.

There have been many studies on the functional heterogeneity of PSC subpopulations with different biomarkers recently. Ikenaga et al. indicated that CD10+ PSCs significantly enhanced the aggressiveness of PCCs compared with CD10- PSCs and were correlated with a poor prognosis of PDAC patients (35). Öhlund et al. reported that PSCs could differentiate into two distinct cancer-associated fibroblasts (CAFs), one (located near tumor cells) expressed higher $\alpha \mathrm{SMA}$ and exhibited a myofibroblast phenotype, while the other (located more distantly from cancer cells) expressed lower $\alpha \mathrm{SMA}$ and secreted higher inflammatory factors like interleukin-6 (IL-6), IL-11 (36). The functional heterogeneity of PSCs was also reported by Tjomsland et al. that PSCs from patients showed disparate hepatocyte growth factor (HGF) production which caused distinct cancer outcomes (37). PSC subsets can also exhibit a tumor suppressor effect. CD271+ PSCs were observed around tumor and were significantly correlated with a better prognosis of PDAC patients (38). This further supported the concept that diverse populations of PSCs exhibit disparate or even opposite functions in cancer. In addition, several other biomarkers of PSCs have been reported recently and deserve further research on heterogeneity. S100A4 was discovered as a new biomarker for cancer-derived PSCs (39, 40). Another marker cadherin-11 was found to be upregulated in activated PSCs and was involved in the migration of PCCs (41). Galectin-1 was overexpressed in PSCs and was involved in enhancing the malignancy of cancer cells and forming an immunosuppressive TME of PDAC (42-44). Yoshida et al. demonstrated that kindlin2 was highly expressed in PSCs and could promote the proliferation and migration of PCCs (45). Higher kindlin-2 expression in stroma was correlated to shorter recurrence-free survival after R0 resection of PDAC (45). More recently, Yeo et al. indicated that p21-activated kinase 1 (PAK1) was expressed in PSCs and could regulate the activation and apoptosis of PSCs. PAK1-knockout mice with PDAC showed an increased survival compared to the control group (46). Biomarkers of PSCs which promote or suppress PDAC were summarized in Table 2.

It is worth noting that, simple inhibition of signaling pathways without considering the heterogeneity of PSCs might cause treatment failure in different PDAC patients. Increasing the identification of PSC biomarkers for different subgroups will

TABLE 2 | PSCs biomarkers related to the development of PDAC.

\begin{tabular}{ll}
\hline Biomarkers & Description \\
\hline Cadherin-11 & CD10 ${ }^{+}$PSCs augment the aggressiveness of PDAC (35). \\
CD10 & CD271 $1^{+}$PSCs are around tumor and are associated with a better prognosis of PDAC (38). \\
CD271 & PSCs can migrate to metastatic sites together with PCCs via circulating blood, which further forms a niche for the metastasis of PDAC (47). \\
Circulating PSCs & Galectin-1 is increased in PSCs and increases PCCs invasiveness (42-44). \\
Galectin-1 & PSCs with different HGF production result in the functional heterogeneity (37). \\
HGF & Kindlin-2 is overexpressed in PSCs and enhances the proliferation and migration of PCCs (45). \\
Kindlin-2 & Palladin is highly expressed in stroma and promotes invasion of PCCs (48). \\
Palladin & P2X7R is correlated with PSCs' activity and collagen deposition (49). \\
P2X7R & PAK1 is expressed in PSCs and regulate the activation and apoptosis of PSCs (46). \\
PAK1 & S100A4 is a new biomarker in activated PSCs (50). \\
S100A4 &
\end{tabular}


not only help gain a better understanding of their heterogeneity and origin but will also facilitate the development of selective therapeutic targeting in PDAC treatment.

\section{THE ROLE OF PSCS IN THE AGGRESSIVENESS OF PDAC}

The poor prognosis of PDAC is attributed to several reasons, among which the highly desmoplastic TME is the major cause of treatment failure of conventional chemotherapy (51-53). The role of TME in tumor progression has received great attention only in recent decades, although the 'seed and soil' theory was first proposed in 1889 (54). The TME of PDAC accounts for up to $90 \%$ of tumor volume and contains ECM, PSCs, endothelial cells, collapsed vessels and immune cells $(55,56)$. Constituting approximately $50 \%$ of the TME, activated PSCs have been considered as one of the most significant cell types in PDAC stroma and have received enormous attention in the recent decades (57-69).

The critical roles of PSCs in PDAC aggressiveness include the ECM production, the regulation of desmoplastic reaction, and the modulation of PDAC malignancy in cell proliferation, migration, invasion, angiogenesis, and drug resistance (70). The importance of the crosstalk between PSCs and PCCs in PDAC progression has been well recognized. activated PSCs release increased levels of various cytokines and growth factors, which regulate the proliferation, migration, and invasion of PCCs $(14,18,71)$. In addition, PCCs release cytokines like IL1, IL-6, colony-stimulating factor 1 (CSF1) and tumor necrosis factor- $\alpha$ (TNF- $\alpha$ ) and growth factors such as TGF- $\beta 1$ and platelet-derived growth factor BB (PDGF-BB), which modulate the activation of PSCs $(13,72,73)$. PSCs also interact with other stroma cells like endothelial cells, immune cells, and neuronal cells, which further contributes to the aggressiveness of PDAC. Figure 2 is a schematic diagram of PSCs' activation procedure and the crosstalk of PSCs, PCCs, and other stromal cells in PDAC progression.

\section{PSCs in Microenvironment Remodeling of PDAC}

PDAC is characterized by a severe desmoplastic reaction as well as the energy metabolism disorders $(74,75)$. As the most prominent cell type in the PDAC-TME, PSCs act an important role in reshaping PDAC-TME both mechanically and metabolically.

\section{PSCs in Mechanical Reprogramming of TME}

Accumulating evidence reveals that physical factors (e.g. tissue pressure, matrix stiffness) are key players with both tumorsupporting and -restraining functions in the development of tumor (76-78). It is well known that PDAC is featured by the rich stroma and severe fibrotic reaction which are attributed to PSC-produced ECM mechanics. The regulation of mechanosensitive ion channels of PSCs, focal adhesion molecules, and cytoskeletal modifications has been shown to act a role in the PSC-mediated mechanobiological remodeling of TME. Fels et al. showed that high interstitial pressure could enhance the activation of PSCs and perpetuate the ECM deposition (79). This positive feedback between activated PSCs and intratumoral pressure could be inhibited by targeting

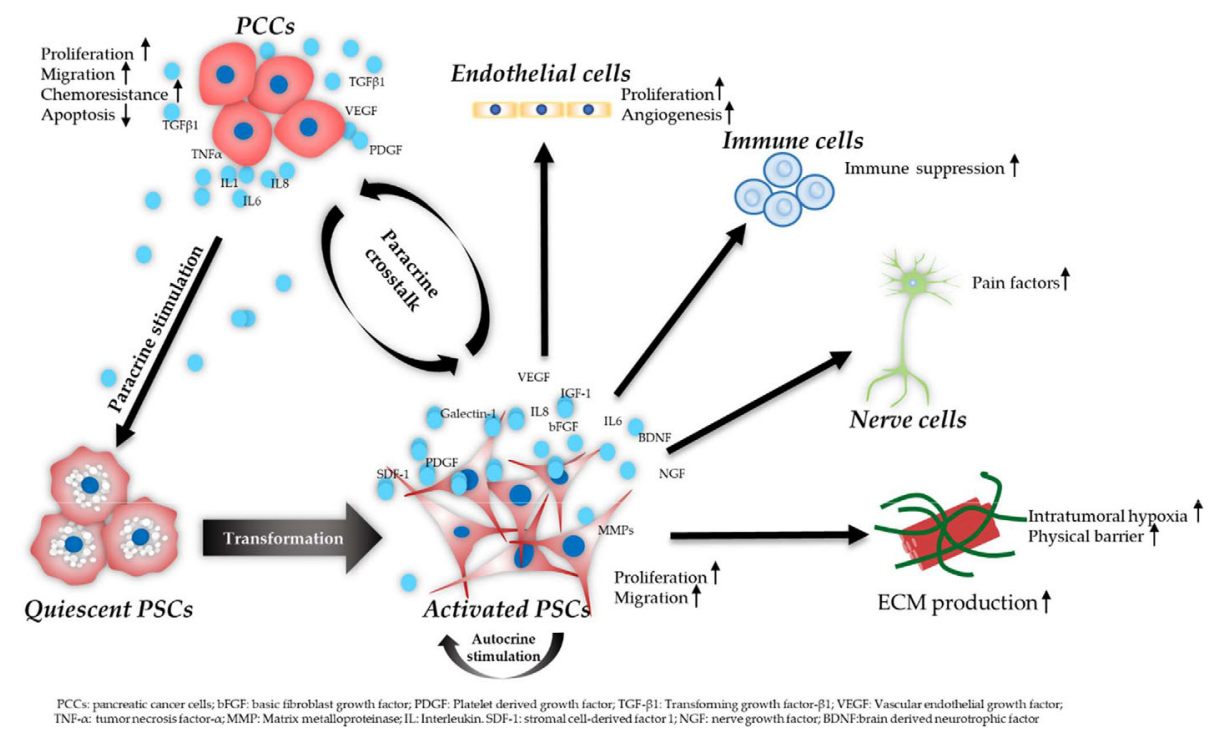

FIGURE 2 | Schematic diagram of PSC activation procedure and the crosstalk of PSCs, PCCs, and other stromal cells. PCCs induce PSC transformation from a quiescent to an activated state by paracrine stimulation. Activated PSCs release various molecules which in turn promote the aggressiveness of PCCs. In addition, PSCs remain in an activated state showing increased migration, proliferation, and ECM production via an autocrine way. PSCs contribute to increased angiogenesis via interacting with endothelial cells. PSCs also secrete neurotrophic factors, leading to pain in PDAC. In addition, PSCs play an important role in creating an immunosuppressive TME via the crosstalk with immune cells. 
canonical transient receptor potential 1 (TRPC1) (79). Another study showed that the TRPC3 and KCa3.1 channels improved the migration and chemotaxis of PSCs (80). Lachowski et al. revealed that matrix rigidity could directly control the activation and durotaxis in PSCs using a physiomimetic system (81). PSCs were shown to overproduce ECM proteins and induce an aggressive phenotype of PCCs via the focal adhesion kinase $(\mathrm{FAK}) / \beta 1$ integrin pathway (82). Moreover, the high secretion of ECM also led to the increased interstitial pressure in PDAC (83), which contributed to vascular atrophy, hypoxia, insufficient blood flow, and depletion of nutrients (84). Two recent studies indicated that under hypoxic condition, PSCs exhibited adaptation to oxidative stress and kept continuously activated, increased migration ability, and released elevated molecules like MMP-2, MMP-3 that influenced the ECM remodeling $(85,86)$. The role of PSCs in remodeling TME mechanically can be further evidenced by the studies using all-trans retinoic acid (ATRA) and tamoxifen. Chronopoulos et al. demonstrated that ATRA could mechanically decrease force-mediated ECM deposition by reducing PSC-produced high traction forces, thereby inhibiting the invasion of PCCs in 3D organotypic models (87). Cortes et al. found that tamoxifen (an agonist of the G protein-coupled estrogen receptor) could inhibit PSC differentiation into myofibroblasts, thereby hampering the PSCs' ability of remodeling the ECM and enhancing invasion of PCCs (88).

Notably, the mechanically remodeled TME also has an ability of suppressing tumor. Rhim et al. showed that simple depletion of stroma components led to a more aggressive tumor with undifferentiated histology, increased vascularity, and heightened proliferation in PDAC mouse models (89). This is further confirmed by a recent study indicating the tumor-restraining role of activated PSCs and desmoplasia in the high-grade PDAC (13).

In summary, the positive feedback between mechanical TME and activated PSCs is a vital player in the progression of PDAC. Reshaping the TME mechanically by targeting PSCs is a promising approach for the treatment of PDAC. In addition, we need to pay special attention to the suppressing role of PSCs and desmoplasia when formulating tumor treatment strategies, especially in high-grade PDAC.

\section{PSCs in Metabolic Remodeling of TME}

In addition to the mechanical factors in the microenvironment, the biochemical components also significantly affect cancer. During tumor development, glutamine addiction and cell autophagy play important roles in tumor cell metabolism. PSCs and PCCs present a mutually promoting relationship in cell growth and metabolism. For instance, upregulation of sonic hedgehog $(\mathrm{SHH})$ induced by oncogenic KRAS mutations in PCCs can activate PSCs. Activated PSCs subsequently stimulate the phosphoinositide 3-kinase (PI3K)/protein kinase $\mathrm{B}(\mathrm{AKT})$ signaling and respiratory activity in the mitochondria of cancer cells, thereby augmenting oxygen availability for PCCs in the hypoxic TME (90). PDAC has poor blood vessel formation, which creates metabolic stress conditions in PCCs and stromal cells. Su et al. revealed that the metabolic stress could reprogram PSCs, thereby differentially regulating adjacent cells in the TME of PDAC (91). PSC-mediated metabolic remodeling of TME can also support the metabolism of cancer cells even under the nutrient-depleted and hypoxic TME. The "reverse Warburg effect" that indicates the role of stromal cells in maintaining cancer cell metabolism is involved in this process. For example, the autophagy of PSCs can induce alanine production, further fueling the tricarboxylic acid (TCA) cycle, non-essential amino acids (NEAA) and lipid biosynthesis in PCCs (92). In addition, Endo et al. revealed that inhibitors of autophagy could markedly reduce the activation of PSCs as well as tumor invasiveness in PDAC mice (93).

Furthermore, exosomes secreted by PSCs are abundant in cellular metabolites like amino acids and palmitate which fuel the TCA cycle in the nutrient-depleted TME, thereby accelerating the progression of PDAC (94). More recently, Shao et al. found that the positive feedback occurred in Caveolin-1-reactive oxygen species (ROS) signaling in PSCs, leading to a conversion from energy metabolism to glycolysis in PSCs (95). Adjacent PCCs then took up the PSC-produced glycolysis products like lactate to perform oxidative phosphorylation (95). As such, blocking the metabolic coupling between PSCs and PCCs may be a promising treatment for PDAC.

Overall, PSCs are the key players in maintaining the energy metabolism of PCCs via autophagy and oxidative stress. More studies are also needed to broaden our understanding and provide novel alternatives to the treatment of PDAC.

\section{PSCs and Chemoresistance}

Recent findings have demonstrated that PSCs play an important role in the chemoresistance of PDAC. PSCs can produce abundant desmoplastic stroma and form a physical barrier preventing the efficacy of chemotherapy drugs, as evidenced by the increased intratumoral drug delivery and penetration after stroma depletion treatment (96-99). Recently, Hessmann et al. found that PSCs showed a drug-scavenging ability by entrapping active gemcitabine (GEM) within the stroma, thus making GEM unavailable for cancer cells (100).

In addition to forming a physical barrier for chemotherapy drugs, PSCs can promote chemoresistance of PDAC by releasing molecules which interact with PCCs $(60,84,101)$. For instance, periostin, released by PSCs, was reported to enhance the resistance of PCCs to GEM and promote the invasiveness of PCCs via the extracellular signal-regulated kinase 1 and 2 (ERK1/2) and FAK/AKT pathways (102). Singh et al. reported that stromal derived factor-1 (SDF-1) released by PSCs could increase the resistance of PCCs to GEM via its receptor C-X-C chemokine receptor type 4 (CXCR4) on cancer cells (103). Additionally, PSC-secreted SDF- $1 \alpha$ was shown to augment the resistance to GEM via ERK1/2 and FAK/AKT pathway in PCCs (104). Amrutkar et al. indicated that PSC-derived fibronectin could induce the drug resistance of PCCs via the ERK1/2 pathway (105). Furthermore, Richards et al. showed that exosomes secreted by PSCs caused GEM chemoresistance in cancer cells by transmitting the mRNA of Snail and miR-146a 
(106). More recently, Xu et al. reported that PSC-secreted HGF increased resistance of PCCs to GEM via the c-Met/PI3K/Akt pathway (107).

\section{PSCs and Metastasis}

Accumulating evidence has indicated that PSCs and PSC-derived factors play a critical role in PDAC metastasis. PSCs have been demonstrated to induce the EMT process, a well-known procedure of cancer metastasis initiation, in PCCs (107-109). Kikuta et al. showed that PCCs co-cultured with PSCs attained EMT features like loose cell contacts, a fibroblast-like shape, enhanced migration, decreased epithelial marker expression and increased mesenchymal markers expression (110). Several PSC-released factors are also involved in the induction of EMT in PCCs, such as MMP3 (35), stromal cell-derived factor-1 (SDF-1) (111), vascular endothelial growth factor (VEGF) (112), TGF- $\beta$ (113), connective tissue growth factor (CTGF) (114), periostin (115), HGF (107) and so on. A recent study by Schnittert et al. indicated that PSCs overexpressed integrin $\alpha 11$ and increased PDAC metastasis (116). Qian et al. revealed that galectin-1-overexpressed PSCs could enhance the invasion and migration of PCCs by secreting paracrine SDF-1 through the nuclear factor- $\kappa \mathrm{B}(\mathrm{NF}-\kappa \mathrm{B})$ pathway (43). Apte's team revealed that PSC-secreted HGF enhanced the aggressiveness of PDAC via its receptor c-MET on cancer cells, and HGF inhibition resulted in a significant reduction of metastasis in mouse models of PDAC (117, 118). The investigation by Tian et al. indicated that PCCs could be induced into a more invasive phenotype by the binding of PCCderived fibroblast growth factor (FGF) to its receptor on PSCs (119). Moreover, a recent research indicated that PSCs overexpressed circRNA hr7:154954255-154998784+ and promoted PDAC metastasis via miR-4459/KIAA0513 axis (120).

PSCs can also migrate to metastatic sites together with PCCs, which further forms a niche for the metastasis of PDAC. A hallmark study by Xu et al. indicated that PSCs from the primary tumor area could even be detected and further lead to a severe stromal reaction in the distant metastatic nodules, thereby creating a metastasis-supportive TME (121). Suetsugu et al. found that after splenic injection of PSCs and PCCs, both types of cells were observed in metastatic sites by tracking PSCs expressing green fluorescence protein (GFP) (122). All these findings further support the "seed and soil" theory with regards to cancer metastasis. Therefore, a recent review by Pang et al. recommended to test circulating PSCs together with circulating tumor cells as potential biomarkers in PDAC (47).

\section{PSCs and Immune Tolerance}

PDAC is also characterized by the evasion of host immune surveillance and several studies have indicated that PSCs also play a significant role in this process (42, 123-125).

Ene-Obong et al. demonstrated that PSC-derived SDF-1 showed a chemotactic effect on CD8+ T cells, thereby hampering their infiltration into tumor areas (126). PSCs were also reported to highly secret TGF- $\beta 1$ and IL-10, which had a suppressive effect on dendritic cells (DCs), thus impeding immune responses in PDAC (127). Additionally, two studies suggested that myeloid-derived suppressor cells (MDSCs) were stimulated to differentiate and expand by PSCs via IL-6/signal transducer and activator of transcription 3 (STAT-3) signaling pathway and formed a TME resistant to immunotherapy $(84,128)$. Moreover, research indicated that the level of MDSCs was upregulated in the TME and was related to a poor prognosis $(124,125)$. The work by Tang et al. revealed that PSC-secreted galectin-1 impeded the activation of $\mathrm{T}$ cells, induced their apoptosis and increased the secretion of cytokine by $\mathrm{T}$ helper type 2 (Th2), thus forming an immunosuppressive TME of PDAC (42). Lunardi et al. demonstrated that PSC-secreted CXCL10 improved recruitment of CXCR3+ regulatory $\mathrm{T}$ cells (Tregs) and reduced cytolysis intermediated by $\mathrm{T}$ cells and natural killer (NK) cells, thereby causing the immunosuppressive and tumor-promoting effects (129). PSCs are also involved in the regulation of mast cells as well as mast cell-mediated tumor growth. Ma et al. reported that PSCs activated mast cells which subsequently released IL-13 and tryptase, thus stimulating the proliferation of PCCs and PSCs (130). In addition, PSCs expressed a variety of Tolllike receptors (TLRs) and reacted to TLR ligands, resulting in the activation of signaling pathways and proinflammatory responses (131). Fibroblast activation protein $\alpha(\mathrm{FAP} \alpha)$ was reported to interfere antitumor immunity. Kraman et al. revealed that depletion of FAP- $\alpha^{+}$cells in stroma induced the immune response-mediated tumor regression in a subcutaneous mouse model of PDAC (132).

Overall, PSCs affect the anti-tumor immune by attenuating the viability of immune cells, impairing the immune response as well as augmenting the immune tolerance of PCCs. Recently, immunotherapy has been effective in cancers like melanoma and non-small cell lung cancer, while similar therapies developed for pancreatic cancer have showed little effects. Given that PDAC has a unique immunosuppressive TME, understanding these complex interactions between PSCs and immune cells will help develop more effective immunotherapies against PDAC.

\section{PSCs and Angiogenesis}

In PDAC, PSCs can secret lots of pro-angiogenic factors, such as VEGF, bFGF, IL-8, PDGF, and periostin, which promote proliferation, survival, and migration of endothelia cells, thereby contributing to angiogenesis (133). Tang et al. found that prokineticin (PK) secreted by aPSCs promoted angiogenesis by inducing the function of the PK/PKR system on endothelial cells (133). Kuninty et al. showed that TGF- $\beta$-activated PSCs induced tube formation (a measure of angiogenesis) of endothelial cells, which could be regulated via the therapeutic miRNA-199a-3p and miRNA-214-3p (134). Patel et al. showed that PSCs increased proliferation and tube formation of microvascular endothelial cells via the $\mathrm{HGF} / \mathrm{c}$-Met pathway (135). In addition, PSCs expressed more type I collagen and VEGF, and showed more pro-angiogenic responses under hypoxia (136). PSCs may have the ability to maintain a balance between pro- and anti-angiogenic responses within PDAC, since PSCs were also reported to release antiangiogenic molecules like thrombospondin-1 (137), vasohibin1 and endostatin (138).

Apart from the signaling pathway, PSC-mediated desmoplasia may also affect the vasculature via inducing matrix stiffness and ECM deposition. Tissue stiffness is well acknowledged to change cell behaviors (e.g. migration, cell-cell adhesion, and proliferation) 
which are necessary for angiogenesis. For example, Bordeleau et al. revealed that elevated matrix stiffness induced invasion of endothelial cells and neovascular formation by upregulating MMPs in endothelial cells (139). In addition, these alterations in endothelial cells could reduce the barrier function of vessels (139). Similarly, Reid et al. revealed that elevated matrix stiffness upregulated $\mathrm{N}$-cadherin expression on the surface of endothelial cells, thus enhancing the interaction between tumor cells and endothelial cells (140). In addition, the dense stroma can compress the vessels, thereby causing the poor vascularization, nutrient depletion, hypoxia and poor delivery of drugs in PDACTME (141). Depletion of PSCs in PDAC led to suppressed angiogenesis, enhanced tumor hypoxia without improving the efficacy of GEM (142). This might be explained by the ECM deposition in the TME covering the local proangiogenic ability of PSCs. Therefore, normalizing, rather than simply depleting the vasculature may be a better strategy to increase the delivery of chemotherapy drugs to tumors.

\section{PSCs and Nerve Interaction}

PSCs are also involved in neural invasion in PDAC progression. $\mathrm{Li}$ et al. demonstrated that activated PSCs induced neurite outgrowth towards PCCs and promoted neural invasion of PCCs (143). More recently, Nan et al. reported that PSCs promoted the perineural invasion of PCCs via the HGF/c-Met pathway (67). In addition, Han et al. reported that PSCs contributed to pain in PDAC by PSC-induced secretion of pain factors from dorsal root ganglia (144). Demir et al. also found that conditioned medium from cancer-associated PSCs could stimulate neuron outgrowth (145).

\section{CURRENT PROGRESS IN TARGETING STRATEGIES}

Although the field of PSCs is young, many researchers have engaged great efforts and several strategies targeting the tumor stroma have been proposed $(43,46,59,102,134,146,147)$. However, the strategy of simple PSC depletion was shown to cause more invasive and undifferentiated PDAC with reduced survival in transgenic mice (148). Therefore, most current strategies have focused on normalizing PSCs or reducing ECM production (137, 149-151). In addition, recent research demonstrated that activated PSCs showed a tumor-suppressing function in high-grade PDAC, and normalizing PSCs might be not suitable for this situation (13). The detailed information of current targeted strategies is summarized in Table 3 . The following paragraphs will mainly focus on the current progress of several promising strategies.

i. Vitamin A derivatives: ATRA is a medication used for the treatment of acne and acute promyelocytic leukemia (174, 175). Although several studies have explored the use of ATRA for the treatment of PDAC, there is no solid tumor indication for the drug. Previous experimental studies have indicated that Vitamin A analogs are able to normalize
PSCs and induce a less aggressive behavior of PCCs. Chronopoulos et al. indicated that ATRA-treated PSCs significantly decreased the PSC-induced matrix remodeling as well as the invasion of PCCs (87). In KPC mice, ATRA was shown to reprise the quiescent state of PSCs, thereby reducing PCCs proliferation and increasing PCCs apoptosis via Wnt- $\beta$-catenin signaling pathway (176). Single treatment of PCCs with ATRA showed no effects on cancer cell aggressiveness, while drug combination of ATRA and chemotherapy drugs like GEM could markedly decrease tumor growth, epithelialmesenchymal transition (EMT) as well as modulating several signaling pathways (e.g. Wnt, $\mathrm{SHH}$ ) in $\mathrm{KPC}$ mice (177). Furthermore, an in-vivo study showed that after treatment with gold nanoparticles containing ATRA and heat-shock protein 47 siRNA, PSCs got normalized and GEM delivery to the tumor was improved in a mouse model of PDAC (178). All these data provide a sufficient theoretical basis for conducting clinical trials. Recently, a trial (NCT03307148) repurposing ATRA as the stromal targeting agent along with GEM and nab-paclitaxel for PDAC is underway and its phase Ib trial (NCT03307148) has showed that ATRA+GEM+nab-paclitaxel treatment in advanced, unresectable PDAC patients is safe and tolerable (179).

ii. Vitamin D (VD) analogs: Epidemiological studies have indicated the importance of VD in PDAC progression. Scientists from America and Australia have revealed that the risk and mortality rate of PDAC are negatively related to ultraviolet radiation (UVR), a main source of VD (180183). More recently, Garland et al. showed that the incidence of PDAC in countries with low UVR is about 6 times that in countries with high UVR, indicating an inverse association between cloud-adjusted UVR and PDAC incidence (184). In addition, the relationship among VD, VD receptor (VDR) and prognosis of PDAC were reported. Investigators demonstrated that low expression of VDR or low circulating VD level $(<20 \mathrm{ng} / \mathrm{ml})$ was related to a poor prognosis of PDAC (185-187). Gene expression profiling studies demonstrated that PSCs showed a strong expression of VDR (137). Several studies have showed that VD derivatives could reprise the quiescent state of PSCs and reduce the fibrosis in $\mathrm{CP}$ and $\operatorname{PDAC}(137,188)$. Combination therapy of calcipotriol and GEM was shown to reduce the fibrotic reaction in TME and tumor growth, elevate GEM delivery into tumor, and increase survival in KPC mice (137). miR-10a was shown to have a protumorigenic ability (189). Kong et al. found that treatment with VD derivates could markedly inhibit the release of exosomal miR-10a-5p in PSCs, thus reducing its tumorigenic effects on PCCs (190). These data constitute a compelling reason for clinical trials combining VD analogs with chemotherapy in PDAC. Single application of VD derivates seems to be ineffective in PDAC treatment, evidenced by the failure of EB1089 or Arachitol treatment in patients with unresectable PDAC (191, 192). The 
TABLE 3 | Strategies targeting PSCs in TME of PDAC.

\begin{tabular}{|c|c|c|}
\hline Strategies & Descriptions & Main results \\
\hline \multicolumn{3}{|l|}{ Clinical studies } \\
\hline PEGPH2O & HA degradation & Phase Ib: Elevated OS and PFS in PDAC patients (99). \\
\hline IPI-926 & Hedgehog pathway inhibitor & Phase II: Withdrawn for increased mortality (152). \\
\hline Marimastat & MMP inhibitor & Phase II: No extra benefits were found in PDAC patients, compared to GEM alone (153). \\
\hline ATRA & Retinoic acid derivatives & Phase lb: Ongoing, no results released (154). \\
\hline $\begin{array}{l}\text { Cabiralizumab plus } \\
\text { nivolumab }\end{array}$ & Target CSF1R & Phase la/lb: no results published. NCT04191421 \\
\hline Vitamin D3 & Target VDR & Phase III: no results published. NCT03472833, NCT03300921 \\
\hline Paricalcitol & Target VDR & Phase II: no results published. NCT02754726 \\
\hline \multicolumn{3}{|l|}{ Preclinical studies } \\
\hline IPI-926 & Hedgehog pathway inhibitor & Elevated vascular density and concentration of GEM in tumor of KPC mice (155). \\
\hline AZD8542 & Hedgehog pathway inhibitor & Reduced tumor volume and metastasis in an orthotopic model of PDAC (156). \\
\hline Metformin & Repurposed anti-diabetic drugs & Reduced PSC activation, tumor volume and increased GEM efficacy in an orthotopic mice of PDAC (157). \\
\hline Minnelide & TGF $\beta$ signaling inhibitor & $\begin{array}{l}\text { Reduced ECM production, increased vasculature, improved drug delivery in tumor in both spontaneous } \\
\text { KPC mice and PDAC xenografts mice (158). }\end{array}$ \\
\hline Calpeptin & Calpains inhibitor & Reduced PSC activation, decreased fibrosis, tumor volume in PDAC xenografts mice (159). \\
\hline JQ1 \& I-BET151 & BET inhibitors & Attenuated PSC activation and collagen I production in the mouse model of PDAC (160). \\
\hline $\begin{array}{l}\text { Genetical deletion of } \\
\alpha \mathrm{SMA}+\text { cells }\end{array}$ & $\alpha \mathrm{SMA}+$ cells & More aggressive tumors, increased hypoxia and EMT, reduced survival in transgenic PDAC mice (148). \\
\hline $\begin{array}{l}\text { Genetical deletion of } \\
\mathrm{SHH}\end{array}$ & SHH pathway & Undifferentiated malignancies, increased vascularity and proliferation in SHH-deleted PDAC mice (161). \\
\hline PEGPH20 & HA degradation & $\begin{array}{l}\text { Depleted HA, expanded blood vessels and increased chemotherapeutic drug delivery in tumor of PDAC } \\
\text { mice (83). }\end{array}$ \\
\hline Pirfenidone & TGF $\beta$ signaling inhibitor & $\begin{array}{l}\text { Reduced PSC proliferation, collagen production; co-treatment with GEM reduced tumor growth and } \\
\text { hepatic metastasis in PDAC mice (162). }\end{array}$ \\
\hline Olmesartan & Ang $\|$ receptor 1 antagonists & $\begin{array}{l}\text { Decreased PSC proliferation, } \alpha \text { SMA expression, collagen I production, tumor growth in subcutaneous } \\
\text { PDAC mice (163). }\end{array}$ \\
\hline Losartan & Ang $\|$ receptor 1 antagonists & $\begin{array}{l}\text { Decreased stress in solid tumors, improved vascular perfusion, increased chemotherapeutic delivery in } \\
\text { PDAC mice (164). }\end{array}$ \\
\hline ATRA & Retinoic acid derivatives & $\begin{array}{l}\text { Decreased PSC migration, collagen synthesis, leading to an increased apoptosis of surrounding PSCs } \\
\text { (151). }\end{array}$ \\
\hline Calcipotriol & Vitamin D3 derivatives & $\begin{array}{l}\text { Improved intratumoral concentration of drug, decreased tumor size, prolonged survival compared to GEM } \\
\text { alone in KPC mice (137). }\end{array}$ \\
\hline LXA4 & An endogenous bioactive lipid & Reduced PSC activation, fibrosis and tumor growth of in mouse model (150). \\
\hline Fasudil & $\begin{array}{l}\text { Rho-associated protein kinase } \\
\text { inhibitor }\end{array}$ & $\begin{array}{l}\text { Reduced PSC activation, decreased collagen deposition, increased GEM delivery, improved OS in PDAC } \\
\text { mouse model (146). }\end{array}$ \\
\hline AZ13381758 & CXCR2 inhibitor & Reduced collagen I/III, lowered metastasis, increased OS in PDAC mouse model (165). \\
\hline AV3 & Integrin $\alpha 5$ inhibitor & $\begin{array}{l}\text { Reduced desmoplasia, decompressed blood vasculature, improved GEM efficacy in patient-derived } \\
\text { xenograft PDAC model (62). }\end{array}$ \\
\hline AMD3100 & CXCR4 antagonist & Increased T cell infiltration, reduced tumor growth in PDAC mouse model (166). \\
\hline AMG102 & HGF inhibitor & Reduced tumor volume and metastasis when treated together with GEM in orthotopic mice of PDAC (117). \\
\hline CSF1 & Strong inducer of PSC deactivation & In mesenchymal PDAC, CSF1 deactivated PSCs thereby reducing the tumor-restraining effect of PSCs. \\
\hline Exendin-4 & $\begin{array}{l}\text { Glucagon-like peptide-1 receptor } \\
\text { agonist }\end{array}$ & Decreased PSC proliferation and migration, reduced PCC migration, invasion and proliferation (167). \\
\hline Resveratrol & $\begin{array}{l}\text { Natural polyphenol with antioxidant } \\
\text { and anticancer effects }\end{array}$ & $\begin{array}{l}\text { Inhibited hypoxia-induced PSC activation, blocked PSCs-PCCs crosstalk, and decreased malignant } \\
\text { progression of PDAC and stromal desmoplasia in a KPC mouse model (168). }\end{array}$ \\
\hline ICG-001 & $\beta$-catenin/CBP inhibitor & Suppressed activation of PSCs and PSC-induced migration of PCCs (169). \\
\hline XL888 & Hsp90 inhibitor & Reduced PSC activation and enhanced the efficacy of anti-PD-1 blockade in tumor bearing mice (170). \\
\hline Curcumin & $\begin{array}{l}\text { Turmeric polyphenol derivates of } \\
\text { rhizomes of Curcuma longa }\end{array}$ & Reduced $\alpha S M A$, type I collagen, and fibronectin and diminished PSC activation (171). \\
\hline Emodin & Important component of Aloe vera & $\begin{array}{l}\text { Reduced expression of } \alpha \text { SMA, type I collagen, and fibronectin in PSCs and enhanced the efficacy of } \\
\text { chemotherapeutic drugs for PDAC (172). }\end{array}$ \\
\hline Pantoprazole & Proton pump inhibitor & Decreased collagen secretion from PSCs and proliferation of PCCs (173). \\
\hline
\end{tabular}

combination therapy with VD analogs and chemotherapy shows good prospects. Blanke et al. performed a phase II trial evaluating the effects of calcitriol with docetaxel in 25 patients with inoperable PDAC (193). Patients treated with this combination therapy showed an increase in time to progression compared to those received single docetaxel treatment (193). Another phase II study (NCT02754726) was also conducted to evaluate the combination strategy (nivolumab, cisplatin, nab-paclitaxel, paricalcitol, GEM) and the preliminary results were encouraging. The objective response rate in 24 patients was $83 \%$, with a median PFS of 8.17 months and a median overall survival (OS) of 15.3 months (194). Other clinical trials (NCT03472833, NCT03331562, NCT03520790, NCT03300921, NCT03883919, NCT03519308, NCT03415854) are also underway. Taken together, combination strategy of VD analogs and chemotherapy drugs are promising in the treatment of PDAC. 
iii. PEGPH20: Buckway et al. indicated that removal of stromal barrier by hyaluronidase treatment enhanced the penetration of chemotherapy drug in tumor bearing mice (96). PEGPH20, a drug based on the recombinant human hyaluronidase enzyme, was found to reduce the malignant behavior of tumor and promote the survival of mice when combined with GEM in PDAC model (98). Systemic administration of PEGPH20 ablated stromal hyaluronic acid, resulting in increased intratumoral concentration of GEM and an almost doubled overall survival in the KPC mouse model (83). In addition, a phase I trial (NCT01453153) indicated promising results that PDAC patients who were treated with PEGPH20 plus GEM showed prolonged OS and progression-free survival (PFS) rates (99). In another phase II trial (NCT01839487), the largest improvement in PFS was observed in patients with HA-high tumors who received the drug combination (PEGPH20+nab-paclitaxel+GEM) (195).

iv. $\mathrm{SHH}$ inhibitors: It has been well proved that the $\mathrm{SHH}$ pathway modulates the interaction between PSCs and PCCs (144). A SHH inhibitor, IPI-926, led to reduced tumor growth and metastasis, increased vascular density and intratumoral GEM concentration in orthotopic mouse models of PDAC $(144,155)$. Recently, Hwang et al. reported that AZD8542, a novel hedgehog inhibitor, could reduce tumor volume and metastasis in an orthotopic model of PDAC (156). However, an in-vivo study indicated that tumor from SHH-deleted PDAC mice showed a more invasive behavior (161). In addition, the clinical trial of IPI-926 (phase II) was withdrawn because of the increased mortality in PDAC patients (152). The differences between preclinical and clinical setting might attribute to the complicate pathways involved in the stroma-tumor crosstalk. Since every model has its own limitations, any preclinical results should be thoroughly assessed in different models before taken into clinical setting.

v. Metformin: Metformin, the first-line medication for the treatment of type II diabetes, is one of the guanidine derivatives from Galega officinalis and is able to decrease the level of blood glucose (196). Research has indicated that metformin shows anticancer effects in several cancers, such as breast, ovarian, pancreatic, and colon cancer (197-199). Duan et al. indicated that metformin suppressed paracrinemediated activation of PSCs in the coculture setting of PCCs-PSCs (200). Han et al. revealed that metformin inhibited the PSC-mediated desmoplastic reactions, thus reducing tumor size and improving the perfusion of GEM-loaded magnetic nanoparticles in a murine orthotopic PDAC model (157). More recently, metformin was shown to suppress angiogenesis and increase GEM chemosensitivity via deactivating PSCs in KPC mice (201). Interestingly, Zechner et al. explored the intratumoral heterogeneity of the therapeutical responses to GEM and metformin in a syngeneic orthotopic mouse model. Metformin was shown to inhibit the proliferation of PCCs close to the desmoplastic part, while GEM reduced the proliferation of PCCs which were away from the fibrotic area, indicating the potential role of PSCs in regulating PCCs sensitivity towards metformin or GEM (200).

vi. Angiotensin II (Ang-II) inhibitors: It is well acknowledged that the renin-angiotensin system (RAS) plays a role in the activation of PSCs. Ang-II, a key player in RAS, was reported to promote the proliferation and ECM production of PSCs (202). Therefore, the angiotensin blockers are of therapeutic potential and two Ang-II type I receptor inhibitors have been investigated. The work by Masamune et al. demonstrated that Olmesartan reduced the collagen I production of PSCs and impeded tumor growth in PDAC mouse models (163). The other inhibitor, losartan, was also shown to decrease the solid pressure in tumor and increase the vascular perfusion by reducing the collagen and $\mathrm{HA}$ production in $\mathrm{PDAC}$ mouse models (164).

vii. Pirfenidone: Pirfenidone is a drug for the treatment of idiopathic pulmonary fibrosis. It has also been shown to reduce PSC activation, collagen secretion, thereby attenuating the proliferation and metastasis of PCCs in a mouse model of PDAC (203). Kozono et al. indicated that compared to treatment with GEM alone, pirfenidone plus GEM could diminish tumor progression by decreasing the activation state of PSCs (203). In another study conducted by Suklabaidya et al., the combination strategy (pirfenidone plus $\mathrm{N}$-acetyl cysteine) diminished the fibrotic reaction, as well as the growth and metastasis of PCCs in a hamster model of PDAC (162).

viii. CSF1: Since the stroma has the dual effects of promoting and suppressing cancer, simple stroma depletion will bring unpredictable effects in the treatment of PDAC. The circulating level of CSF1 was reported to be elevated in PDAC, and the higher CSF1 level was markedly correlated with more advanced stages of PDAC $(204,205)$. Recently, a hallmark study by Steins et al. further proved this opinion. They showed that collagens and activated PSCs were lower in the stroma of high-grade mesenchymal PDAC. Further investigation indicated that proliferative and $\alpha S M A-$ positive PSCs had a tumor-restraining effect and highgrade PDAC could deactivate PSCs via the secretion of CSF1 (13). Therefore, targeting CSF1 or CSF1R is a promising strategy to maintain a tumor-suppressing TME with abundant collagens and activated PSCs in high-grade PDAC tumors. In addition, the strategy of reprogramming PSCs into a quiescent state should be carefully re-evaluated in high-grade tumor, because it may produce completely different results.

ix. Some other promising targets: Several other strategies have also been reported recently. For example, the endogenous lipid Lipoxin A4 was demonstrated to impede the activation procedure of PSCs, thereby decreasing the aggressiveness and tumor volume of PDAC in vivo (150). Orozco et al. indicated that galectin-1-depleted resulted in the attenuated activation of PSCs, enhanced $\mathrm{T}$ cell infiltration, and diminished tumor metastases in mouse models of PDAC (44). Moreover, Yoshida et al. found that calpeptin, a 
calpain inhibitor, decreased PSC activation and reduced the aggressiveness of PDAC by disrupting the crosstalk between PSCs and PCCs in a mouse xenograft model (159). Yan et al. indicated that exendin-4, a glucagon-like peptide-1 receptor agonist, could inactivate PSCs, thus suppressing PCC proliferation and invasion (167). Xiao et al. reported that resveratrol inhibited hypoxia-induced activation of PSCs, thereby blocking the PSCs-PCCs crosstalk, and decreasing the malignant progression of PDAC and stromal desmoplasia in a KPC mouse model (168). ICG001, a cAMP-responsive element binding (CREB)-binding protein $(\mathrm{CBP}) / \beta$-catenin antagonist, was shown to suppress the activation of PSCs and PSC-induced migration of PCCs (169). Zhang et al. reported that a heat shock protein 90 (Hsp90) inhibitor, XL888, reduced PSC activation, and enhanced the efficacy of anti-programmed cell death protein 1 (PD-1) blockade in tumor-bearing mice (170). Attempts are also made in reprogramming PSCs by miRNA, a potential therapeutic target (206). Kwon et al. showed that miRNA-29 was reduced in the activation procedure of PSCs, and restoring the expression of miRNA-29 in PSCs decreased the desmoplastic reaction in TME as well as the aggressiveness of PDAC (207). In another study by Asama et al., miRNA let-7d impeded the activation of PSCs by targeting thrombospondin 1, and subsequently decreased pancreatic fibrosis (208). Chen et al. indicated that PSCs treated with nitric oxide could reduce the production of dense stroma, thereby significantly enhancing the efficacy of GEM-loaded liposomes, and inhibiting tumor growth in both subcutaneous and orthotopic tumor mouse models (97). Turaga et al. found that ProAgio specifically depleted PSCs and eliminated angiogenesis, thus increasing drug delivery and GEM efficacy in PDAC (209). Moreover, a study by German cancer research center showed that date palm fruit extracts could reduce PSC-induced fibrosis, decrease PSCs proliferation, and reverse the fibrotic phenotype of PSCs, thereby possibly enhancing the efficacy of known chemotherapy drugs (210).

\section{CHALLENGES}

It can be clearly seen from the above that, the role of PSCs in PDAC progression and the stroma-targeted strategies have been well acknowledged. Nevertheless, it must be admitted that little benefit has been observed so far in the clinical trials. PSCtargeted strategy has also met several challenges which need to be overcome in the future.

Recently, PSCs have been reported to be heterogeneous, and the heterogeneity of PSCs has received great attention. Ikenaga et al. reported that $\mathrm{CD} 10^{+}$PSCs were more effective than $\mathrm{CD} 10^{-}$ PSCs in inducing invasion and proliferation of PCCs (35). Another research demonstrated two distinct PSCs: a) one subtype expressed high $\alpha$ SMA and displayed a myofibroblast phenotype; b) another subtype showed lower $\alpha$ SMA expression and instead released higher IL-6 and other chemokines (36). As such, different PSC subtypes may have completely distinct effects on PDAC development, and this heterogeneity needs to be carefully considered in the development of novel stroma targeting strategies in PDAC. More research on PSC subtypes is needed to further progress this field.

The complexity of pathways mediating PSCs-PCCs crosstalk is another challenge, although several candidate pathways were reported to be potential targets for novel therapeutic strategies. For example, the clinical trial of IPI-926 (a hedgehog inhibitor) was terminated due to increased mortality of patients (152), though it worked well in pre-clinical experiments $(144,155)$. Therefore, when testing new therapeutic approaches, it is critical to replicate as much as possible the conditions (e.g. hypoxia) inside human pancreatic malignancy. Hopefully, many new research models have been developed recently. For instance, Boj et al. developed organoid models of PDAC which realized heterogeneity, 3D structure, and crosstalk between different cell types (211). Finally, new therapies need to be thoroughly evaluated in different models before we take them into clinical, since each model has its own limitations.

Although most strategies have focused on deactivating PSCs or stroma, the tumor-restraining role of PSCs in PDAC should be carefully considered when designing novel strategies. This is confirmed by the failure of simple stroma depletion strategy. In addition, a recent study further proved the importance of PSCs and stroma in suppressing high-grade mesenchymal PDAC (13). The failure of several PSCs/stroma-targeting studies is likely due to the neglect of the tumor-restrictive properties of PSCs/stroma. Therefore, the strategy of reprogramming PSCs into a quiescent state should be carefully re-evaluated especially in high-grade PDAC.

\section{CONCLUSION}

As we demonstrated in this review, PSC-produced collagenous stroma is recognized as a major factor of aggressiveness and chemoresistance in PDAC. The crosstalk among PSCs, PCCs, and other stromal cells also plays a key role in immune tolerance, chemoresistance, angiogenesis, metastasis, and recurrence of PDAC. Modulating PSCs can reprogram the cancer 'soil' into a tumorsuppressive niche, thereby turning foes into friends that suppress PDAC progression. Additionally, since the standard chemotherapy targeting cancer cells alone has displayed disappointing outcomes, novel stroma-targeting strategies together with conventional chemotherapy has become the research hotspot and various strategies have been proposed. Nevertheless, these therapeutic strategies need to be further validated in appropriate, clinically relevant pre-clinical models before they are assessed in clinic. Hopefully, many preclinical studies demonstrate that normalization of PSCs and PSC-derived ECM can reprogram the stroma into a less tumor-supportive phenotype which further decreases the aggressiveness of PDAC. Several clinical trials are underway and will finally determine the viability and efficacy of these therapeutic approaches against PDAC. Notably, given the tumor-restraining ability of PSCs and stroma, the strategy of deactivating PSCs might cause negative effects and should be 
carefully re-evaluated in high-grade PDAC. More research is also needed to deepen the understanding of the dual role of PSCs in the development of PDAC.

\section{AUTHOR CONTRIBUTIONS}

Investigation and writing-original paper, $\mathrm{YW}$ and CZ. Equal contribution; writing-review and editing, all authors. Supervision, AB, KJ, and JW. Project administration, AB and

\section{REFERENCES}

1. Watari N, Hotta Y, Mabuchi Y. Morphological studies on a vitamin Astoring cell and its complex with macrophage observed in mouse pancreatic tissues following excess vitamin A administration. Okajimas Folia Anat Jpn (1982) 58(4-6):837-58. doi: 10.2535/ofaj1936.58.4-6_837

2. Apte MV, Haber PS, Applegate TL, Norton ID, McCaughan GW, Korsten MA, et al. Periacinar stellate shaped cells in rat pancreas: identification, isolation, and culture. Gut (1998) 43(1):128-33. doi: 10.1136/gut.43.1.128

3. Bachem MG, Schneider E, Gross H, Weidenbach H, Schmid RM, Menke A, et al. Identification, culture, and characterization of pancreatic stellate cells in rats and humans. Gastroenterology (1998) 115(2):421-32. doi: 10.1016/ s0016-5085(98)70209-4

4. Apte MV, Park S, Phillips PA, Santucci N, Goldstein D, Kumar RK, et al. Desmoplastic reaction in pancreatic cancer - Role of pancreatic stellate cells. Pancreas (2004) 29(3):179-87. doi: 10.1097/00006676-200410000-00002

5. Apte MV, Wilson JS. Mechanisms of pancreatic fibrosis. Digestive Dis (2004) 22(3):273-9. doi: 10.1159/000082799

6. Mews P, Phillips P, Fahmy R, Korsten M, Pirola R, Wilson J, et al. Pancreatic stellate cells respond to inflammatory cytokines: potential role in chronic pancreatitis. Gut (2002) 50(4):535-41. doi: 10.1136/gut.50.4.535

7. Haber PS, Keogh GW, Apte MV, Moran CS, Stewart NL, Crawford DHG, et al. Activation of pancreatic stellate cells in human and experimental pancreatic fibrosis. Am J Pathol (1999) 155(4):1087-95. doi: 10.1016/s00029440(10)65211-x

8. Siegel RL, Miller KD, Jemal A. Cancer statistics, 2019. CA Cancer J Clin (2019) 69(1):7-34. doi: 10.3322/caac.21551

9. McGuigan A, Kelly P, Turkington RC, Jones C, Coleman HG, McCain RS. Pancreatic cancer: A review of clinical diagnosis, epidemiology, treatment and outcomes. World J Gastroenterol (2018) 24(43):4846-61. doi: 10.3748/ wjg.v24.i43.4846

10. Rawla P, Sunkara T, Gaduputi V. Epidemiology of Pancreatic Cancer: Global Trends, Etiology and Risk Factors. World J Oncol (2019) 10(1):10-27. doi: 10.14740/wjon1166

11. Vonlaufen A, Phillips PA, Xu ZH, Goldstein D, Pirola RC, Wilson JS, et al. Pancreatic stellate cells and pancreatic cancer cells: An unholy alliance. Cancer Res (2008) 68(19):7707-10. doi: 10.1158/0008-5472.Can08-1132

12. Erkan M, Adler G, Apte MV, Bachem MG, Buchholz M, Detlefsen S, et al. StellaTUM: current consensus and discussion on pancreatic stellate cell research. Gut (2012) 61(2):172-8. doi: 10.1136/gutjnl-2011-301220

13. Steins A, van Mackelenbergh MG, van der Zalm AP, Klaassen R, Serrels B, Goris SG, et al. High-grade mesenchymal pancreatic ductal adenocarcinoma drives stromal deactivation through CSF-1. EMBO Rep (2020) 21(5):e48780. doi: 10.15252/embr.201948780

14. Apte MV, Wilson JS, Lugea A, Pandol SJ. A Starring Role for Stellate Cells in the Pancreatic Cancer Microenvironment. Gastroenterology (2013) 144 (6):1210-9. doi: 10.1053/j.gastro.2012.11.037

15. Duner S, Lindman JL, Ansari D, Gundewar C, Andersson R. Pancreatic Cancer: The Role of Pancreatic Stellate Cells in Tumor Progression. Pancreatology (2010) 10(6):673-81. doi: 10.1159/000320711

16. Allam A, Thomsen AR, Gothwal M, Saha D, Maurer J, Brunner TB. Pancreatic stellate cells in pancreatic cancer: In focus. Pancreatology (2017) 17(4):514-22. doi: 10.1016/j.pan.2017.05.390
JD'H. All authors have read and agreed to the published version of the manuscript. All authors contributed to the article and approved the submitted version.

\section{FUNDING}

This research has been supported by the Chinese Scholarship Council to YW (201708320343) and to CZ (201708320342).

17. Nielsen MFB, Mortensen MB, Detlefsen S. Identification of markers for quiescent pancreatic stellate cells in the normal human pancreas. Histochem Cell Biol (2017) 148(4):359-80. doi: 10.1007/s00418-0171581-5

18. Fu Y, Liu S, Zeng S, Shen H. The critical roles of activated stellate cellsmediated paracrine signaling, metabolism and onco-immunology in pancreatic ductal adenocarcinoma. Mol Cancer (2018) 17(1):62. doi: 10.1186/s12943-018-0815-Z

19. Bynigeri RR, Jakkampudi A, Jangala R, Subramanyam C, Sasikala M, Rao GV, et al. Pancreatic stellate cell: Pandora's box for pancreatic disease biology. World J Gastroenterol (2017) 23(3):382-405. doi: 10.3748/ wjg.v23.i3.382

20. Apte MV, Haber PS, Darby SJ, Rodgers SC, McCaughan GW, Korsten MA, et al. Pancreatic stellate cells are activated by proinflammatory cytokines: implications for pancreatic fibrogenesis. Gut (1999) 44(4):534-41. doi: 10.1136/gut.44.4.534

21. Asahina K, Tsai SY, Li P, Ishii M, Maxson REJr, Sucov HM, et al. Mesenchymal origin of hepatic stellate cells, submesothelial cells, and perivascular mesenchymal cells during mouse liver development. Hepatology (2009) 49(3):998-1011. doi: 10.1002/hep.22721

22. Enzan H, Himeno H, Hiroi M, Kiyoku H, Saibara T, Onishi S. Development of hepatic sinusoidal structure with special reference to the Ito cells. Microsc Res Tech (1997) 39(4):336-49. doi: 10.1002/(SICI)1097-0029(19971115) 39:4<336::AID-JEMT4>3.0.CO;2-F

23. Cassiman D, Barlow A, Vander Borght S, Libbrecht L, Pachnis V. Hepatic stellate cells do not derive from the neural crest. J Hepatol (2006) 44 (6):1098-104. doi: 10.1016/j.jhep.2005.09.023

24. Cassiman D, Roskams T. Beauty is in the eye of the beholder: emerging concepts and pitfalls in hepatic stellate cell research. J Hepatol (2002) 37 (4):527-35. doi: 10.1016/s0168-8278(02)00263-5

25. Niki T, Pekny M, Hellemans K, Bleser PD, Berg KV, Vaeyens F, et al. Class VI intermediate filament protein nestin is induced during activation of rat hepatic stellate cells. Hepatology (1999) 29(2):520-7. doi: 10.1002/ hep. 510290232

26. Kiassov AP, Van Eyken P, van Pelt JF, Depla E, Fevery J, Desmet VJ, et al. Desmin expressing nonhematopoietic liver cells during rat liver development: an immunohistochemical and morphometric study. Differentiation (1995) 59(4):253-8. doi: 10.1046/j.1432-0436.1995.5940253.x

27. Vassy J, Rigaut JP, Briane D, Kraemer M. Confocal microscopy immunofluorescence localization of desmin and other intermediate filament proteins in fetal rat livers. Hepatology (1993) 17(2):293-300. doi: 10.1002/hep.1840170221

28. Xue R, Jia K, Wang JX, Yang LX, Wang YB, Gao LY, et al. A Rising Star in Pancreatic Diseases: Pancreatic Stellate Cells. Front Physiol (2018) 9:754. doi: 10.3389/fphys.2018.00754

29. Scarlett CJ, Colvin EK, Pinese M, Chang DK, Morey AL, Musgrove EA, et al. Recruitment and activation of pancreatic stellate cells from the bone marrow in pancreatic cancer: a model of tumor-host interaction. PloS One (2011) 6 (10):e26088. doi: 10.1371/journal.pone.0026088

30. Sparmann G, Kruse ML, Hofmeister-Mielke N, Koczan D, Jaster R, Liebe S, et al. Bone marrow-derived pancreatic stellate cells in rats. Cell Res (2010) 20 (3):288-98. doi: 10.1038/cr.2010.10

31. Ino K, Masuya M, Tawara I, Miyata E, Oda K, Nakamori Y, et al. Monocytes infiltrate the pancreas via the MCP-1/CCR2 pathway and differentiate 
into stellate cells. PloS One (2014) 9(1):e84889. doi: 10.1371/journal. pone. 0084889

32. Paulo JA, Kadiyala V, Banks PA, Conwell DL, Steen H. Mass spectrometrybased quantitative proteomic profiling of human pancreatic and hepatic stellate cell lines. Genomics Proteomics Bioinf (2013) 11(2):105-13. doi: 10.1016/j.gpb.2013.01.009

33. Asahina K, Zhou B, Pu WT, Tsukamoto H. Septum transversum-derived mesothelium gives rise to hepatic stellate cells and perivascular mesenchymal cells in developing mouse liver. Hepatology (2011) 53 (3):983-95. doi: 10.1002/hep.24119

34. Verbeke C. Morphological heterogeneity in ductal adenocarcinoma of the pancreas - Does it matter? Pancreatology (2016) 16(3):295-301. doi: 10.1016/j.pan.2016.02.004

35. Ikenaga N, Ohuchida K, Mizumoto K, Cui L, Kayashima T, Morimatsu K, et al. CD10+ pancreatic stellate cells enhance the progression of pancreatic cancer. Gastroenterology (2010) 139(3):1041-51, 1051 e1-8. doi: 10.1053/ j.gastro.2010.05.084

36. Ohlund D, Handly-Santana A, Biffi G, Elyada E, Almeida AS, Ponz-Sarvise M, et al. Distinct populations of inflammatory fibroblasts and myofibroblasts in pancreatic cancer. J Exp Med (2017) 214(3):579-96. doi: 10.1084/jem.20162024

37. Tjomsland V, Aasrum M, Christoffersen T, Gladhaug IP. Functional heterogeneity in tumor-derived human pancreatic stellate cells: Differential expression of HGF and implications for mitogenic signaling and migration in pancreatic cancer cells. Oncotarget (2017) 8(42):71672-84. doi: 10.18632/oncotarget.17800

38. Fujiwara K, Ohuchida K, Mizumoto K, Shindo K, Eguchi D, Kozono S, et al. CD271(+) subpopulation of pancreatic stellate cells correlates with prognosis of pancreatic cancer and is regulated by interaction with cancer cells. PloS One (2012) 7(12):e52682. doi: 10.1371/journal.pone.0052682

39. Farrow B, Rowley D, Dang T, Berger DH. Characterization of tumor-derived pancreatic stellate cells. J Surg Res (2009) 157(1):96-102. doi: 10.1016/ j.jss.2009.03.064

40. Zechner D, Knapp N, Bobrowski A, Radecke T, Genz B, Vollmar B. Diabetes increases pancreatic fibrosis during chronic inflammation. Exp Biol Med (Maywood) (2014) 239(6):670-6. doi: 10.1177/1535370214527890

41. Birtolo C, Pham H, Morvaridi S, Chheda C, Go VL, Ptasznik A, et al. Cadherin-11 Is a Cell Surface Marker Up-Regulated in Activated Pancreatic Stellate Cells and Is Involved in Pancreatic Cancer Cell Migration. Am J Pathol (2017) 187(1):146-55. doi: 10.1016/j.ajpath.2016.09.012

42. Tang D, Yuan Z, Xue X, Lu Z, Zhang Y, Wang H, et al. High expression of Galectin-1 in pancreatic stellate cells plays a role in the development and maintenance of an immunosuppressive microenvironment in pancreatic cancer. Int J Cancer (2012) 130(10):2337-48. doi: 10.1002/ijc.26290

43. Qian D, Lu Z, Xu Q, Wu P, Tian L, Zhao L, et al. Galectin-1-driven upregulation of SDF-1 in pancreatic stellate cells promotes pancreatic cancer metastasis. Cancer Lett (2017) 397:43-51. doi: 10.1016/j.canlet.2017.03.024

44. Orozco CA, Martinez-Bosch N, Guerrero PE, Vinaixa J, Dalotto-Moreno T, Iglesias $\mathrm{M}$, et al. Targeting galectin-1 inhibits pancreatic cancer progression by modulating tumor-stroma crosstalk. Proc Natl Acad Sci USA (2018) 115 (16):E3769-78. doi: 10.1073/pnas.1722434115

45. Yoshida N, Masamune A, Hamada S, Kikuta K, Takikawa T, Motoi F, et al. Kindlin-2 in pancreatic stellate cells promotes the progression of pancreatic cancer. Cancer Lett (2017) 390:103-14. doi: 10.1016/j.canlet.2017.01.008

46. Yeo D, Phillips P, Baldwin GS, He H, Nikfarjam M. Inhibition of group 1 p21-activated kinases suppresses pancreatic stellate cell activation and increases survival of mice with pancreatic cancer. Int J Cancer (2017) 140 (9):2101-11. doi: 10.1002/ijc.30615

47. Pang TCY, Xu Z, Pothula S, Becker T, Goldstein D, Pirola RC, et al. Circulating pancreatic stellate (stromal) cells in pancreatic cancer-a fertile area for novel research. Carcinogenesis (2017) 38(6):588-91. doi: 10.1093/ carcin/bgx030

48. Goicoechea SM, Garcia-Mata R, Staub J, Valdivia A, Sharek L, McCulloch $\mathrm{CG}$, et al. Palladin promotes invasion of pancreatic cancer cells by enhancing invadopodia formation in cancer-associated fibroblasts. Oncogene (2014) 33 (10):1265-73. doi: 10.1038/onc.2013.68

49. Giannuzzo A, Saccomano M, Napp J, Ellegaard M, Alves F, Novak I. Targeting of the P2X7 receptor in pancreatic cancer and stellate cells. Int $J$ Cancer (2016) 139(11):2540-52. doi: 10.1002/ijc.30380
50. Tian L, Lu ZP, Cai BB, Zhao LT, Qian D, Xu QC, et al. Activation of pancreatic stellate cells involves an EMT-like process. Int J Oncol (2016) 48 (2):783-92. doi: 10.3892/ijo.2015.3282

51. Chu GC, Kimmelman AC, Hezel AF, DePinho RA. Stromal biology of pancreatic cancer. J Cell Biochem (2007) 101(4):887-907. doi: 10.1002/jcb.21209

52. Vennin C, Murphy KJ, Morton JP, Cox TR, Pajic M, Timpson P. Reshaping the Tumor Stroma for Treatment of Pancreatic Cancer. Gastroenterology (2018) 154(4):820-38. doi: 10.1053/j.gastro.2017.11.280

53. Neesse A, Bauer CA, Ohlund D, Lauth M, Buchholz M, Michl P, et al. Stromal biology and therapy in pancreatic cancer: ready for clinical translation? Gut (2019) 68(1):159-71. doi: 10.1136/gutjnl-2018-316451

54. Paget S. The distribution of secondary growths in cancer of the breast. 1889. Cancer Metastasis Rev (1989) 8(2):98-101.

55. Kong X, Li L, Li Z, Xie K. Targeted destruction of the orchestration of the pancreatic stroma and tumor cells in pancreatic cancer cases: molecular basis for therapeutic implications. Cytokine Growth Factor Rev (2012) 23(6):34356. doi: 10.1016/j.cytogfr.2012.06.006

56. Feig C, Gopinathan A, Neesse A, Chan DS, Cook N, Tuveson DA. The Pancreas Cancer Microenvironment. Clin Cancer Res (2012) 18(16):426676. doi: 10.1158/1078-0432.Ccr-11-3114

57. Farran B, Nagaraju GP. The dynamic interactions between the stroma, pancreatic stellate cells and pancreatic tumor development: Novel therapeutic targets. Cytokine Growth Factor Rev (2019) 48:11-23. doi: $10.1016 /$ j.cytogfr.2019.07.001

58. Xiao Y, Zhang H, Ma Q, Huang R, Lu J, Liang X, et al. YAP1-mediated pancreatic stellate cell activation inhibits pancreatic cancer cell proliferation. Cancer Lett (2019) 462:51-60. doi: 10.1016/j.canlet.2019.07.015

59. Horioka K, Ohuchida K, Sada M, Zheng B, Moriyama T, Fujita H, et al. Suppression of CD51 in pancreatic stellate cells inhibits tumor growth by reducing stroma and altering tumor-stromal interaction in pancreatic cancer. Int J Oncol (2016) 48(4):1499-508. doi: 10.3892/ijo.2016.3374

60. Dalin S, Sullivan MR, Lau AN, Grauman-Boss B, Mueller HS, Kreidl E, et al. Deoxycytidine Release from Pancreatic Stellate Cells Promotes Gemcitabine Resistance. Cancer Res (2019) 79(22):5723-33. doi: 10.1158/00085472.CAN-19-0960

61. Wen Z, Liu Q, Wu J, Xu B, Wang J, Liang L, et al. Fibroblast activation protein alpha-positive pancreatic stellate cells promote the migration and invasion of pancreatic cancer by CXCL1-mediated Akt phosphorylation. Ann Transl Med (2019) 7(20):532. doi: 10.21037/atm.2019.09.164

62. Kuninty PR, Bansal R, De Geus SWL, Mardhian DF, Schnittert J, van Baarlen J, et al. ITGA5 inhibition in pancreatic stellate cells attenuates desmoplasia and potentiates efficacy of chemotherapy in pancreatic cancer. Sci Adv (2019) 5(9):eaax2770. doi: 10.1126/sciadv.aax2770

63. Yuan Y, Jiang JY, Wang JM, Sun J, Li C, Liu BQ, et al. BAG3-positive pancreatic stellate cells promote migration and invasion of pancreatic ductal adenocarcinoma. J Cell Mol Med (2019) 23(8):5006-16. doi: 10.1111/ jcmm.14352

64. Junliang L, Lili W, Xiaolong L, Xuguang L, Huanwen W, Zhiyong L. Highmolecular-weight hyaluronan produced by activated pancreatic stellate cells promotes pancreatic cancer cell migration via paracrine signaling. Biochem Biophys Res Commun (2019) 515(3):493-8. doi: 10.1016/j.bbrc.2019.05.167

65. Hwang HJ, Oh MS, Lee DW, Kuh HJ. Multiplex quantitative analysis of stroma-mediated cancer cell invasion, matrix remodeling, and drug response in a 3D co-culture model of pancreatic tumor spheroids and stellate cells. J Exp Clin Cancer Res (2019) 38(1):258. doi: 10.1186/s13046-019-1225-9

66. Wang HC, Lin YL, Hsu CC, Chao YJ, Hou YC, Chiu TJ, et al. Pancreatic stellate cells activated by mutant KRAS-mediated PAI-1 upregulation foster pancreatic cancer progression via IL-8. Theranostics (2019) 9(24):7168-83. doi: $10.7150 /$ thno.36830

67. Nan L, Qin T, Xiao Y, Qian W, Li J, Wang Z, et al. Pancreatic Stellate Cells Facilitate Perineural Invasion of Pancreatic Cancer via HGF/c-Met Pathway. Cell Transplant (2019) 28(9-10):1289-98. doi: 10.1177/0963689719851772

68. Tang $\mathrm{D}, \mathrm{Wu} \mathrm{Q}$, Yuan $\mathrm{Z}, \mathrm{Xu}$ J, Zhang $\mathrm{H}$, Jin $\mathrm{Z}$, et al. Identification of key pathways and gene changes in primary pancreatic stellate cells after crosstalk with pancreatic cancer cells (BXPC-3) using bioinformatics analysis. Neoplasma (2019) 66(3):446-58. doi: 10.4149/neo_2018_180925N714

69. Zhou L, Husted H, Moore T, Lu M, Deng D, Liu Y, et al. Suppression of stromal-derived Dickkopf-3 (DKK3) inhibits tumor progression and 
prolongs survival in pancreatic ductal adenocarcinoma. Sci Transl Med (2018) 10(464):1-31. doi: 10.1126/scitranslmed.aat3487

70. Kanat O, Ertas H. Shattering the castle walls: Anti-stromal therapy for pancreatic cancer. World J Gastrointestinal Oncol (2018) 10(8):202-10. doi: 10.4251/wjgo.v10.i8.202

71. Omary MB, Lugea A, Lowe AW, Pandol SJ. The pancreatic stellate cell: a star on the rise in pancreatic diseases. J Clin Invest (2007) 117(1):50-9. doi: $10.1172 /$ jci30082

72. Kota J, Hancock J, Kwon J, Korc M. Pancreatic cancer: Stroma and its current and emerging targeted therapies. Cancer Lett (2017) 391:38-49. doi: 10.1016/j.canlet.2016.12.035

73. Farran B, Nagaraju GP. The dynamic interactions between the stroma, pancreatic stellate cells and pancreatic tumor development: Novel therapeutic targets. Cytokine Growth Factor Rev (2019) 48:11-23. doi: 10.1016/j.cytogfr.2019.07.001

74. Whatcott CJ, Diep CH, Jiang P, Watanabe A, LoBello J, Sima C, et al. Desmoplasia in Primary Tumors and Metastatic Lesions of Pancreatic Cancer. Clin Cancer Res (2015) 21(15):3561-8. doi: 10.1158/1078-0432.CCR-14-1051

75. Sousa CM, Kimmelman AC. The complex landscape of pancreatic cancer metabolism. Carcinogenesis (2014) 35(7):1441-50. doi: 10.1093/carcin/ bgu097

76. Levental KR, Yu H, Kass L, Lakins JN, Egeblad M, Erler JT, et al. Matrix crosslinking forces tumor progression by enhancing integrin signaling. Cell (2009) 139(5):891-906. doi: 10.1016/j.cell.2009.10.027

77. Schrader J, Gordon-Walker TT, Aucott RL, van Deemter M, Quaas A, Walsh S, et al. Matrix stiffness modulates proliferation, chemotherapeutic response, and dormancy in hepatocellular carcinoma cells. Hepatology (2011) 53(4):1192-205. doi: 10.1002/hep.24108

78. Gkretsi V, Stylianopoulos T. Cell Adhesion and Matrix Stiffness: Coordinating Cancer Cell Invasion and Metastasis. Front Oncol (2018) 8:145. doi: $10.3389 /$ fonc. 2018.00145

79. Fels B, Nielsen N, Schwab A. Role of TRPC1 channels in pressure-mediated activation of murine pancreatic stellate cells. Eur Biophys J (2016) 45(7):65770. doi: 10.1007/s00249-016-1176-4

80. Storck H, Hild B, Schimmelpfennig S, Sargin S, Nielsen N, Zaccagnino A, et al. Ion channels in control of pancreatic stellate cell migration. Oncotarget (2017) 8(1):769-84. doi: 10.18632/oncotarget.13647

81. Lachowski D, Cortes E, Pink D, Chronopoulos A, Karim SA, Morton PM, et al. Substrate Rigidity Controls Activation and Durotaxis in Pancreatic Stellate Cells. Sci Rep (2017) 7(1):2506. doi: 10.1038/s41598-017-02689-x

82. Berchtold S, Grunwald B, Kruger A, Reithmeier A, Hahl T, Cheng T, et al. Collagen type $\mathrm{V}$ promotes the malignant phenotype of pancreatic ductal adenocarcinoma. Cancer Lett (2015) 356(2 Pt B):721-32. doi: 10.1016/ j.canlet.2014.10.020

83. Provenzano PP, Cuevas C, Chang AE, Goel VK, Von Hoff DD, Hingorani SR. Enzymatic targeting of the stroma ablates physical barriers to treatment of pancreatic ductal adenocarcinoma. Cancer Cell (2012) 21(3):418-29. doi: $10.1016 /$ j.ccr.2012.01.007

84. Schnittert J, Bansal R, Prakash J. Targeting Pancreatic Stellate Cells in Cancer. Trends Cancer (2019) 5(2):128-42. doi: 10.1016/j.trecan.2019.01.001

85. Estaras M, Martinez-Morcillo S, Garcia A, Martinez R, Estevez M, PerezLopez M, et al. Pancreatic stellate cells exhibit adaptation to oxidative stress evoked by hypoxia. Biol Cell (2020) 112(10):280-99. doi: 10.1111/ boc. 202000020

86. Nielsen N, Kondratska K, Ruck T, Hild B, Kovalenko I, Schimmelpfennig S, et al. TRPC6 channels modulate the response of pancreatic stellate cells to hypoxia. Pflugers Arch (2017) 469(12):1567-77. doi: 10.1007/s00424-0172057-0

87. Chronopoulos A, Robinson B, Sarper M, Cortes E, Auernheimer V, Lachowski D, et al. ATRA mechanically reprograms pancreatic stellate cells to suppress matrix remodelling and inhibit cancer cell invasion. Nat Commun (2016) 7:12630. doi: 10.1038/ncomms 12630

88. Cortes E, Sarper M, Robinson B, Lachowski D, Chronopoulos A, Thorpe SD, et al. GPER is a mechanoregulator of pancreatic stellate cells and the tumor microenvironment. EMBO Rep (2019) 20(1):e46556. doi: 10.15252/ embr.201846556

89. Rhim AD, Oberstein PE, Thomas DH, Mirek ET, Palermo CF, Sastra SA, et al. Stromal elements act to restrain, rather than support, pancreatic ductal adenocarcinoma. Cancer Cell (2014) 25(6):735-47. doi: 10.1016/ j.ccr.2014.04.021

90. Tape CJ, Ling S, Dimitriadi M, McMahon KM, Worboys JD, Leong HS, et al. Oncogenic KRAS Regulates Tumor Cell Signaling via Stromal Reciprocation. Cell (2016) 165(4):910-20. doi: 10.1016/j.cell.2016.03.029

91. Su HY, Waldron RT, Gong R, Ramanujan VK, Pandol SJ, Lugea A. The Unfolded Protein Response Plays a Predominant Homeostatic Role in Response to Mitochondrial Stress in Pancreatic Stellate Cells. PloS One (2016) 11(2):e0148999. doi: 10.1371/journal.pone.0148999

92. Sousa CM, Biancur DE, Wang X, Halbrook CJ, Sherman MH, Zhang L, et al Pancreatic stellate cells support tumour metabolism through autophagic alanine secretion. Nature (2016) 536(7617):479-83. doi: 10.1038/ nature19084

93. Endo S, Nakata K, Ohuchida K, Takesue S, Nakayama H, Abe T, et al. Autophagy Is Required for Activation of Pancreatic Stellate Cells, Associated With Pancreatic Cancer Progression and Promotes Growth of Pancreatic Tumors in Mice. Gastroenterology (2017) 152(6):1492-506.e24. doi: 10.1053/j.gastro.2017.01.010

94. Zhao H, Yang L, Baddour J, Achreja A, Bernard V, Moss T, et al. Tumor microenvironment derived exosomes pleiotropically modulate cancer cell metabolism. Elife (2016) 5:e10250. doi: 10.7554/eLife.10250

95. Shao S, Qin T, Qian W, Yue Y, Xiao Y, Li X, et al. Positive feedback in Cav-1ROS signalling in PSCs mediates metabolic coupling between PSCs and tumour cells. J Cell Mol Med (2020) 24(16):9397-408. doi: 10.1111/ jcmm.15596

96. Buckway B, Wang Y, Ray A, Ghandehari H. Overcoming the stromal barrier for targeted delivery of HPMA copolymers to pancreatic tumors. Int J Pharm (2013) 456(1):202-11. doi: 10.1016/j.ijpharm.2013.07.067

97. Chen X, Jia F, Li Y, Deng Y, Huang Y, Liu W, et al. Nitric oxide-induced stromal depletion for improved nanoparticle penetration in pancreatic cancer treatment. Biomaterials (2020) 246:119999. doi: 10.1016/ j.biomaterials.2020.119999

98. Jacobetz MA, Chan DS, Neesse A, Bapiro TE, Cook N, Frese KK, et al Hyaluronan impairs vascular function and drug delivery in a mouse model of pancreatic cancer. Gut (2013) 62(1):112-20. doi: 10.1136/gutjnl-2012302529

99. Hingorani SR, Harris WP, Beck JT, Berdov BA, Wagner SA, Pshevlotsky EM, et al. Phase Ib Study of PEGylated Recombinant Human Hyaluronidase and Gemcitabine in Patients with Advanced Pancreatic Cancer. Clin Cancer Res (2016) 22(12):2848-54. doi: 10.1158/1078-0432.CCR-15-2010

100. Hessmann E, Patzak MS, Klein L, Chen N, Kari V, Ramu I, et al. Fibroblast drug scavenging increases intratumoural gemcitabine accumulation in murine pancreas cancer. Gut (2018) 67(3):497-507. doi: 10.1136/gutjnl2016-311954

101. Cao F, Li J, Sun H, Liu S, Cui Y, Li F. HES 1 is essential for chemoresistance induced by stellate cells and is associated with poor prognosis in pancreatic cancer. Oncol Rep (2015) 33(4):1883-9. doi: 10.3892/or.2015.3789

102. Liu Y, Li F, Gao F, Xing L, Qin P, Liang X, et al. Periostin promotes the chemotherapy resistance to gemcitabine in pancreatic cancer. Tumour Biol (2016) 37(11):15283-91. doi: 10.1007/s13277-016-5321-6

103. Singh S, Srivastava SK, Bhardwaj A, Owen LB, Singh AP. CXCL12-CXCR4 signalling axis confers gemcitabine resistance to pancreatic cancer cells: a novel target for therapy. Br J Cancer (2010) 103(11):1671-9. doi: 10.1038/ sj.bjc. 6605968

104. Zhang H, Wu H, Guan J, Wang L, Ren X, Shi X, et al. Paracrine SDF-1alpha signaling mediates the effects of PSCs on GEM chemoresistance through an IL-6 autocrine loop in pancreatic cancer cells. Oncotarget (2015) 6(5):308597. doi: 10.18632/oncotarget.3099

105. Amrutkar M, Aasrum M, Verbeke CS, Gladhaug IP. Secretion of fibronectin by human pancreatic stellate cells promotes chemoresistance to gemcitabine in pancreatic cancer cells. BMC Cancer (2019) 19(1):596. doi: 10.1186/ s12885-019-5803-1

106. Richards KE, Zeleniak AE, Fishel ML, Wu J, Littlepage LE, Hill R. Cancerassociated fibroblast exosomes regulate survival and proliferation of pancreatic cancer cells. Oncogene (2017) 36(13):1770-8. doi: 10.1038/ onc.2016.353

107. Xu J, Liu S, Yang X, Cao S, Zhou Y. Paracrine HGF promotes EMT and mediates the effects of PSC on chemoresistance by activating c-Met/PI3K/ 
Akt signaling in pancreatic cancer in vitro. Life Sci (2020) p:118523. doi: $10.1016 /$ j.lfs.2020.118523

108. Tang D, Wang D, Yuan Z, Xue X, Zhang Y, An Y, et al. Persistent activation of pancreatic stellate cells creates a microenvironment favorable for the malignant behavior of pancreatic ductal adenocarcinoma. Int J Cancer (2013) 132(5):993-1003. doi: 10.1002/ijc.27715

109. Kikuta K, Masamune A, Watanabe T, Ariga H, Itoh H, Hamada S, et al. Pancreatic stellate cells promote epithelial-mesenchymal transition in pancreatic cancer cells. Biochem Biophys Res Commun (2010) 403(34):380-4. doi: 10.1016/j.bbrc.2010.11.040

110. Kikuta K, Masamune A, Watanabe T, Ariga H, Itoh H, Hamada S, et al. Pancreatic stellate cells promote epithelial-mesenchymal transition in pancreatic cancer cells. Biochem Biophys Res Commun (2010) 403(34):380-4. doi: 10.1016/j.bbrc.2010.11.040

111. Gao Z, Wang X, Wu K, Zhao Y, Hu G. Pancreatic stellate cells increase the invasion of human pancreatic cancer cells through the stromal cell-derived factor-1/CXCR4 axis. Pancreatology (2010) 10(2-3):186-93. doi: 10.1159/ 000236012

112. Erkan M, Reiser-Erkan C, Michalski CW, Deucker S, Sauliunaite D, Streit S, et al. Cancer-stellate cell interactions perpetuate the hypoxia-fibrosis cycle in pancreatic ductal adenocarcinoma. Neoplasia (2009) 11(5):497-508. doi: $10.1593 /$ neo. 81618

113. Lee H, Lim C, Lee J, Kim N, Bang S, Lee H, et al. TGF-beta signaling preserves RECK expression in activated pancreatic stellate cells. $J$ Cell Biochem (2008) 104(3):1065-74. doi: 10.1002/jcb.21692

114. Karger A, Fitzner B, Brock P, Sparmann G, Emmrich J, Liebe S, et al. Molecular insights into connective tissue growth factor action in rat pancreatic stellate cells. Cell Signal (2008) 20(10):1865-72. doi: 10.1016/ j.cellsig.2008.06.016

115. Kanno A, Satoh K, Masamune A, Hirota M, Kimura K, Umino J, et al. Periostin, secreted from stromal cells, has biphasic effect on cell migration and correlates with the epithelial to mesenchymal transition of human pancreatic cancer cells. Int J Cancer (2008) 122(12):2707-18. doi: 10.1002/ ijc. 23332

116. Schnittert J, Bansal R, Mardhian DF, van Baarlen J, Ostman A, Prakash J. Integrin alpha11 in pancreatic stellate cells regulates tumor stroma interaction in pancreatic cancer. FASEB $J$ (2019) 33(5):6609-21. doi: 10.1096/ff.201802336R

117. Pothula SP, Xu Z, Goldstein D, Merrett N, Pirola RC, Wilson JS, et al. Targeting the HGF/c-MET pathway: stromal remodelling in pancreatic cancer. Oncotarget (2017) 8(44):76722-39. doi: 10.18632/oncotarget.20822

118. Pothula SP, Xu Z, Goldstein D, Biankin AV, Pirola RC, Wilson JS, et al. Hepatocyte growth factor inhibition: a novel therapeutic approach in pancreatic cancer. Br J Cancer (2016) 114(3):269-80. doi: 10.1038/ bjc. 2015.478

119. Tian X, Chen G, Zhou S, Henne-Bruns D, Bachem M, Kornmann M. Interactions of pancreatic cancer and stellate cells are mediated by FGFR1III isoform expression. Hepatogastroenterology (2012) 59(117):1604-8. doi: 10.5754/hge10366

120. Shao F, Cai M, Fan FF, Huang M, Tao Y, Wang C, et al. Overexpression of circRNA chr7:154954255-154998784+ in cancer-associated pancreatic stellate cells promotes the growth and metastasis of pancreatic cancer by targeting the miR-4459/KIAA0513 axis. Am J Transl Res (2020) 12(9):5048-63.

121. Xu ZH, Vonlaufen A, Phillips PA, Fiala-Beer E, Zhang XG, Yang L, et al. Role of Pancreatic Stellate Cells in Pancreatic Cancer Metastasis. Am J Pathol (2010) 177(5):2585-96. doi: 10.2353/ajpath.2010.090899

122. Suetsugu A, Snyder CS, Moriwaki H, Saji S, Bouvet M, Hoffman RM. Imaging the Interaction of Pancreatic Cancer and Stellate Cells in the Tumor Microenvironment during Metastasis. Anticancer Res (2015) 35 (5):2545-51.

123. Incio J, Liu H, Suboj P, Chin SM, Chen IX, Pinter M, et al. Obesity-Induced Inflammation and Desmoplasia Promote Pancreatic Cancer Progression and Resistance to Chemotherapy. Cancer Discovery (2016) 6(8):852-69. doi: 10.1158/2159-8290.CD-15-1177

124. Gabitass RF, Annels NE, Stocken DD, Pandha HA, Middleton GW. Elevated myeloid-derived suppressor cells in pancreatic, esophageal and gastric cancer are an independent prognostic factor and are associated with significant elevation of the Th2 cytokine interleukin-13. Cancer Immunol Immunother (2011) 60(10):1419-30. doi: 10.1007/s00262-011-1028-0

125. Markowitz J, Brooks TR, Duggan MC, Paul BK, Pan X, Wei L, et al. Patients with pancreatic adenocarcinoma exhibit elevated levels of myeloid-derived suppressor cells upon progression of disease. Cancer Immunol Immunother (2015) 64(2):149-59. doi: 10.1007/s00262-014-1618-8

126. Ene-Obong A, Clear AJ, Watt J, Wang J, Fatah R, Riches JC, et al. Activated pancreatic stellate cells sequester CD8+ T cells to reduce their infiltration of the juxtatumoral compartment of pancreatic ductal adenocarcinoma. Gastroenterology (2013) 145(5):1121-32. doi: 10.1053/j.gastro.2013.07.025

127. Wu Q, Tian Y, Zhang J, Zhang H, Gu F, Lu Y, et al. Functions of pancreatic stellate cell-derived soluble factors in the microenvironment of pancreatic ductal carcinoma. Oncotarget (2017) 8(60):102721-38. doi: 10.18632/ oncotarget.21970

128. Mace TA, Bloomston M, Lesinski GB. Pancreatic cancer-associated stellate cells: A viable target for reducing immunosuppression in the tumor microenvironment. Oncoimmunology (2013) 2(7):e24891. doi: 10.4161/ onci.24891

129. Lunardi S, Jamieson NB, Lim SY, Griffiths KL, Carvalho-Gaspar M, Al-Assar O, et al. IP-10/CXCL10 induction in human pancreatic cancer stroma influences lymphocytes recruitment and correlates with poor survival. Oncotarget (2014) 5 (22):11064-80. doi: 10.18632/oncotarget.2519

130. Ma Y, Hwang RF, Logsdon CD, Ullrich SE. Dynamic mast cell-stromal cell interactions promote growth of pancreatic cancer. Cancer Res (2013) 73 (13):3927-37. doi: 10.1158/0008-5472.CAN-12-4479

131. Masamune A, Kikuta K, Watanabe T, Satoh K, Satoh A, Shimosegawa T. Pancreatic stellate cells express Toll-like receptors. J Gastroenterol (2008) 43 (5):352-62. doi: 10.1007/s00535-008-2162-0

132. Kraman M, Bambrough PJ, Arnold JN, Roberts EW, Magiera L, Jones JO, et al. Suppression of antitumor immunity by stromal cells expressing fibroblast activation protein-alpha. Science (2010) 330(6005):827-30. doi: $10.1126 /$ science. 1195300

133. Tang D, Wang DR, Yuan ZX, Xue XF, Zhang Y, An Y, et al. Persistent activation of pancreatic stellate cells creates a microenvironment favorable for the malignant behavior of pancreatic ductal adenocarcinoma. Int $J$ Cancer (2013) 132(5):993-1003. doi: 10.1002/ijc.27715

134. Kuninty PR, Bojmar L, Tjomsland V, Larsson M, Storm G, Ostman A, et al. MicroRNA-199a and -214 as potential therapeutic targets in pancreatic stellate cells in pancreatic tumor. Oncotarget (2016) 7(13):16396-408. doi: 10.18632/oncotarget.7651

135. Patel MB, Pothula SP, Xu Z, Lee AK, Goldstein D, Pirola RC, et al. The role of the hepatocyte growth factor/c-MET pathway in pancreatic stellate cellendothelial cell interactions: antiangiogenic implications in pancreatic cancer. Carcinogenesis (2014) 35(8):1891-900. doi: 10.1093/carcin/bgu122

136. Masamune A, Kikuta K, Watanabe T, Satoh K, Hirota M, Shimosegawa T. Hypoxia stimulates pancreatic stellate cells to induce fibrosis and angiogenesis in pancreatic cancer. Am J Physiol Gastrointest Liver Physiol (2008) 295(4):G709-17. doi: 10.1152/ajpgi.90356.2008

137. Sherman MH, Yu RT, Engle DD, Ding N, Atkins AR, Tiriac H, et al. Vitamin D Receptor-Mediated Stromal Reprogramming Suppresses Pancreatitis and Enhances Pancreatic Cancer Therapy. Cell (2014) 159(1):80-93. doi: 10.1016/j.cell.2014.08.007

138. Brammer RD, Bramhall SR, Eggo MC. Endostatin expression in pancreatic tissue is modulated by elastase. Br J Cancer (2005) 92(1):89-93. doi: 10.1038/ sj.bjc.6602234

139. Bordeleau F, Mason BN, Lollis EM, Mazzola M, Zanotelli MR, Somasegar S, et al. Matrix stiffening promotes a tumor vasculature phenotype. Proc Natl Acad Sci U.S.A. (2017) 114(3):492-7. doi: 10.1073/pnas.1613855114

140. Reid SE, Kay EJ, Neilson LJ, Henze AT, Serneels J, McGhee EJ, et al. Tumor matrix stiffness promotes metastatic cancer cell interaction with the endothelium. EMBO J (2017) 36(16):2373-89. doi: 10.15252/embj. 201694912

141. Subarsky P, Hill RP. The hypoxic tumour microenvironment and metastatic progression. Clin Exp Metastasis (2003) 20(3):237-50. doi: 10.1023/ a: 1022939318102

142. Ozdemir BC, Pentcheva-Hoang T, Carstens JL, Zheng X, Wu CC, Simpson TR, et al. Depletion of carcinoma-associated fibroblasts and fibrosis induces 
immunosuppression and accelerates pancreas cancer with reduced survival. Cancer Cell (2014) 25(6):719-34. doi: 10.1016/j.ccr.2014.04.005

143. Li X, Wang Z, Ma Q, Xu Q, Liu H, Duan W, et al. Sonic hedgehog paracrine signaling activates stromal cells to promote perineural invasion in pancreatic cancer. Clin Cancer Res (2014) 20(16):4326-38. doi: 10.1158/10780432.CCR-13-3426

144. Han L, Ma J, Duan W, Zhang L, Yu S, Xu Q, et al. Pancreatic stellate cells contribute pancreatic cancer pain via activation of sHH signaling pathway. Oncotarget (2016) 7(14):18146-58. doi: 10.18632/oncotarget.7776

145. Demir IE, Ceyhan GO, Rauch U, Altintas B, Klotz M, Muller MW, et al. The microenvironment in chronic pancreatitis and pancreatic cancer induces neuronal plasticity. Neurogastroenterol Motil (2010) 22(4):480-90, e112-3. doi: $10.1111 / j .1365-2982.2009 .01428 . x$

146. Whatcott CJ, Ng S, Barrett MT, Hostetter G, Von Hoff DD, Han H. Inhibition of ROCK1 kinase modulates both tumor cells and stromal fibroblasts in pancreatic cancer. PloS One (2017) 12(8):e0183871. doi: 10.1371/journal.pone.0183871

147. Zhang Y, Yue D, Cheng L, Huang A, Tong N, Cheng P. Vitamin A-coupled liposomes carrying TLR4-silencing shRNA induce apoptosis of pancreatic stellate cells and resolution of pancreatic fibrosis. J Mol Med (Berl) (2018) 96 (5):445-58. doi: 10.1007/s00109-018-1629-6

148. Ozdemir BC, Pentcheva-Hoang T, Carstens JL, Zheng X, Wu CC, Simpson TR, et al. Depletion of Carcinoma-Associated Fibroblasts and Fibrosis Induces Immunosuppression and Accelerates Pancreas Cancer with Reduced Survival. Cancer Cell (2015) 28(6):831-3. doi: 10.1016/j.ccell.2015.11.002

149. Prakash J. Cancer-Associated Fibroblasts: Perspectives in Cancer Therapy. Trends Cancer (2016) 2(6):277-9. doi: 10.1016/j.trecan.2016.04.005

150. Schnittert J, Heinrich MA, Kuninty PR, Storm G, Prakash J. Reprogramming tumor stroma using an endogenous lipid lipoxin A4 to treat pancreatic cancer. Cancer Lett (2018) 420:247-58. doi: 10.1016/j.canlet.2018.01.072

151. Froeling FEM, Feig C, Chelala C, Dobson R, Mein CE, Tuveson DA, et al. Retinoic Acid-Induced Pancreatic Stellate Cell Quiescence Reduces Paracrine Wnt-beta-Catenin Signaling to Slow Tumor Progression. Gastroenterology (2011) 141(4):1486-U503. doi: 10.1053/j.gastro.2011.06.047

152. Amakye D, Jagani Z, Dorsch M. Unraveling the therapeutic potential of the Hedgehog pathway in cancer. Nat Med (2013) 19(11):1410-22. doi: 10.1038/ nm.3389

153. Bramhall SR, Schulz J, Nemunaitis J, Brown PD, Baillet M, Buckels JA. A double-blind placebo-controlled, randomised study comparing gemcitabine and marimastat with gemcitabine and placebo as first line therapy in patients with advanced pancreatic cancer. Br J Cancer (2002) 87(2):161-7. doi: 10.1038/sj.bjc.6600446

154. Kocher H, Propper DJ, Alabaf S, Mousa K, North B, Papoutsaki V, et al. STAR_PAC: A Phase 1B study repurposing ATRA as stromal targeting agent along with gemcitabine and nab $\neg$ Paclitaxel for pancreatic cancer. Pancreatology (2016) 16(3, Supplement):S4-5. doi: 10.1016/j.pan.2016.04.019

155. Olive KP, Jacobetz MA, Davidson CJ, Gopinathan A, McIntyre D, Honess D, et al. Inhibition of Hedgehog signaling enhances delivery of chemotherapy in a mouse model of pancreatic cancer. Science (2009) 324(5933):1457-61. doi: $10.1126 /$ science. 1171362

156. Hwang RF, Moore TT, Hattersley MM, Scarpitti M, Yang B, Devereaux E, et al. Inhibition of the hedgehog pathway targets the tumor-associated stroma in pancreatic cancer. Mol Cancer Res (2012) 10(9):1147-57. doi: 10.1158/1541-7786.MCR-12-0022

157. Han H, Hou Y, Chen X, Zhang P, Kang M, Jin Q, et al. Metformin-Induced Stromal Depletion to Enhance the Penetration of Gemcitabine-Loaded Magnetic Nanoparticles for Pancreatic Cancer Targeted Therapy. J Am Chem Soc (2020) 142(10):4944-54. doi: 10.1021/jacs.0c00650

158. Banerjee S, Modi S, McGinn O, Zhao X, Dudeja V, Ramakrishnan S, et al. Impaired Synthesis of Stromal Components in Response to Minnelide Improves Vascular Function, Drug Delivery, and Survival in Pancreatic Cancer. Clin Cancer Res (2016) 22(2):415-25. doi: 10.1158/1078-0432.CCR-15-1155

159. Yoshida M, Miyasaka Y, Ohuchida K, Okumura T, Zheng B, Torata N, et al. Calpain inhibitor calpeptin suppresses pancreatic cancer by disrupting cancer-stromal interactions in a mouse xenograft model. Cancer Sci (2016) 107(10):1443-52. doi: 10.1111/cas.13024

160. Kumar K, DeCant BT, Grippo PJ, Hwang RF, Bentrem DJ, Ebine K, et al. BET inhibitors block pancreatic stellate cell collagen I production and attenuate fibrosis in vivo. JCI Insight (2017) 2(3):e88032. doi: 10.1172/ jci.insight. 88032

161. Rhim AD, Oberstein PE, Thomas DH, Mirek ET, Palermo CF, Sastra SA, et al. Stromal Elements Act to Restrain, Rather Than Support, Pancreatic Ductal Adenocarcinoma. Cancer Cell (2014) 25(6):735-47. doi: 10.1016/ j.ccr.2014.04.021

162. Suklabaidya S, Das B, Ali SA, Jain S, Swaminathan S, Mohanty AK, et al. Characterization and use of HapT1-derived homologous tumors as a preclinical model to evaluate therapeutic efficacy of drugs against pancreatic tumor desmoplasia. Oncotarget (2016) 7(27):41825-42. doi: 10.18632/oncotarget. 9729

163. Masamune A, Hamada S, Kikuta K, Takikawa T, Miura S, Nakano E, et al. The angiotensin II type I receptor blocker olmesartan inhibits the growth of pancreatic cancer by targeting stellate cell activities in mice. Scand $J$ Gastroenterol (2013) 48(5):602-9. doi: 10.3109/00365521.2013.777776

164. Chauhan VP, Martin JD, Liu H, Lacorre DA, Jain SR, Kozin SV, et al. Angiotensin inhibition enhances drug delivery and potentiates chemotherapy by decompressing tumour blood vessels. Nat Commun (2013) 4:2516. doi: 10.1038/ncomms3516

165. Steele CW, Karim SA, Leach JDG, Bailey P, Upstill-Goddard R, Rishi L, et al. CXCR2 Inhibition Profoundly Suppresses Metastases and Augments Immunotherapy in Pancreatic Ductal Adenocarcinoma. Cancer Cell (2016) 29(6):832-45. doi: 10.1016/j.ccell.2016.04.014

166. Feig C, Jones JO, Kraman M, Wells RJ, Deonarine A, Chan DS, et al. Targeting CXCL12 from FAP-expressing carcinoma-associated fibroblasts synergizes with anti-PD-L1 immunotherapy in pancreatic cancer. Proc Natl Acad Sci USA (2013) 110(50):20212-7. doi: 10.1073/pnas.1320318110

167. Yan M, Shen M, Xu L, Huang J, He G, An M, et al. Inactivation of Pancreatic Stellate Cells by Exendin-4 Inhibits the Migration and Invasion of Pancreatic Cancer Cells. Onco Targets Ther (2020) 13:9455-63. doi: 10.2147/OTT.S259853

168. Xiao Y, Qin T, Sun L, Qian W, Li J, Duan W, et al. Resveratrol Ameliorates the Malignant Progression of Pancreatic Cancer by Inhibiting Hypoxiainduced Pancreatic Stellate Cell Activation. Cell Transplant (2020) 29:1-14. doi: $10.1177 / 0963689720929987.963689720929987$.

169. Che M, Kweon SM, Teo JL, Yuan YC, Melstrom LG, Waldron RT, et al. Targeting the CBP/beta-Catenin Interaction to Suppress Activation of Cancer-Promoting Pancreatic Stellate Cells. Cancers (Basel) (2020) 12 (6):1476. doi: 10.3390/cancers 12061476

170. Zhang Y, Ware MB, Zaidi MY, Ruggieri AN, Olson BM, Komar H, et al. Heat shock protein-90 inhibition alters activation of pancreatic stellate cells and enhances the efficacy of PD-1 blockade in pancreatic cancer. Mol Cancer Ther (2020). doi: 10.1158/1535-7163.MCT-19-0911

171. Lin Z, Zheng LC, Zhang HJ, Tsang SW, Bian ZX. Anti-fibrotic effects of phenolic compounds on pancreatic stellate cells. BMC Complement Altern Med (2015) 15:259. doi: 10.1186/s12906-015-0789-y

172. Liu A, Chen H, Tong H, Ye S, Qiu M, Wang Z, et al. Emodin potentiates the antitumor effects of gemcitabine in pancreatic cancer cells via inhibition of nuclear factor-kappaB. Mol Med Rep (2011) 4(2):221-7. doi: 10.3892/ mmr.2011.414

173. Tozzi M, Sorensen CE, Magni L, Christensen NM, Bouazzi R, Buch CM, et al. Proton Pump Inhibitors Reduce Pancreatic Adenocarcinoma Progression by Selectively Targeting $\mathrm{H}(+), \mathrm{K}(+)$-ATPases in Pancreatic Cancer and Stellate Cells. Cancers (Basel) (2020) 12(3):640. doi: 10.3390/cancers12030640

174. Lo-Coco F, Avvisati G, Vignetti M, Thiede C, Orlando SM, Iacobelli S, et al. Retinoic acid and arsenic trioxide for acute promyelocytic leukemia. $\mathrm{N} \mathrm{Engl} \mathrm{J}$ Med (2013) 369(2):111-21. doi: 10.1056/NEJMoa1300874

175. Leyden JJ, Shalita A, Thiboutot D, Washenik K, Webster G. Topical retinoids in inflammatory acne: a retrospective, investigator-blinded, vehiclecontrolled, photographic assessment. Clin Ther (2005) 27(2):216-24. doi: $10.1016 /$ j.clinthera.2005.02.009

176. Froeling FE, Feig C, Chelala C, Dobson R, Mein CE, Tuveson DA, et al. Retinoic acid-induced pancreatic stellate cell quiescence reduces paracrine Wnt-beta-catenin signaling to slow tumor progression. Gastroenterology (2011) 141(4):1486-97, 1497 e1-14. doi: 10.1053/j.gastro.2011.06.047

177. Carapuca EF, Gemenetzidis E, Feig C, Bapiro TE, Williams MD, Wilson AS, et al. Anti-stromal treatment together with chemotherapy targets multiple signalling pathways in pancreatic adenocarcinoma. J Pathol (2016) 239 (3):286-96. doi: 10.1002/path.4727 
178. Han X, Li Y, Xu Y, Zhao X, Zhang Y, Yang X, et al. Reversal of pancreatic desmoplasia by re-educating stellate cells with a tumour microenvironmentactivated nanosystem. Nat Commun (2018) 9(1):3390. doi: 10.1038/s41467018-05906-x

179. Kocher HM, Basu B, Froeling FEM, Sarker D, Slater S, Carlin D, et al. Phase I clinical trial repurposing all-trans retinoic acid as a stromal targeting agent for pancreatic cancer. Nat Commun (2020) 11(1):4841. doi: 10.1038/s41467020-18636-w

180. Grant WB. An estimate of premature cancer mortality in the U.S. due to inadequate doses of solar ultraviolet-B radiation. Cancer (2002) 94(6):186775. doi: $10.1002 / \mathrm{cncr} \cdot 10427$

181. Neale RE, Youlden DR, Krnjacki L, Kimlin MG, van der Pols JC. Latitude variation in pancreatic cancer mortality in Australia. Pancreas (2009) 38 (4):387-90. doi: 10.1097/MPA.0b013e31819975f4

182. Mohr SB, Garland CF, Gorham ED, Grant WB, Garland FC. Ultraviolet B irradiance and vitamin $\mathrm{D}$ status are inversely associated with incidence rates of pancreatic cancer worldwide. Pancreas (2010) 39(5):669-74. doi: 10.1097/ MPA.0b013e3181ce654d

183. Tran B, Whiteman DC, Webb PM, Fritschi L, Fawcett J, Risch HA, et al. Association between ultraviolet radiation, skin sun sensitivity and risk of pancreatic cancer. Cancer Epidemiol (2013) 37(6):886-92. doi: 10.1016/j.canep.2013.08.013

184. Garland CF, Cuomo RE, Gorham ED, Zeng K, Mohr SB. Cloud cover-adjusted ultraviolet B irradiance and pancreatic cancer incidence in 172 countries. $J$ Steroid Biochem Mol Biol (2016) 155:257-63. doi: 10.1016/j.jsbmb.2015.04.004

185. Wang K, Dong M, Sheng W, Liu Q, Yu D, Dong Q, et al. Expression of vitamin D receptor as a potential prognostic factor and therapeutic target in pancreatic cancer. Histopathology (2015) 67(3):386-97. doi: 10.1111/his.12663

186. Cho M, Peddi PF, Ding K, Chen L, Thomas D, Wang J, et al. Vitamin D deficiency and prognostics among patients with pancreatic adenocarcinoma. J Transl Med (2013) 11:206. doi: 10.1186/1479-5876-11-206

187. Mukai Y, Yamada D, Eguchi H, Iwagami Y, Asaoka T, Noda T, et al. Vitamin D Supplementation is a Promising Therapy for Pancreatic Ductal Adenocarcinoma in Conjunction with Current Chemoradiation Therapy. Ann Surg Oncol (2018) 25(7):1868-79. doi: 10.1245/s10434-018-6431-8

188. Wallbaum P, Rohde S, Ehlers L, Lange F, Hohn A, Bergner C, et al. Antifibrogenic effects of vitamin D derivatives on mouse pancreatic stellate cells. World J Gastroenterol (2018) 24(2):170-8. doi: 10.3748/wjg.v24.i2.170

189. Weiss FU, Marques IJ, Woltering JM, Vlecken DH, Aghdassi A, Partecke LI, et al. Retinoic acid receptor antagonists inhibit miR-10a expression and block metastatic behavior of pancreatic cancer. Gastroenterology (2009) 137 (6):2136-45.e1-7. doi: 10.1053/j.gastro.2009.08.065

190. Kong F, Li L, Wang G, Deng X, Li Z, Kong X. VDR signaling inhibits cancerassociated-fibroblasts' release of exosomal miR-10a-5p and limits their supportive effects on pancreatic cancer cells. Gut (2019) 68(5):950-1. doi: 10.1136/gutjnl-2018-316627

191. Evans TR, Colston KW, Lofts FJ, Cunningham D, Anthoney DA, Gogas H, et al. A phase II trial of the vitamin D analogue Seocalcitol (EB1089) in patients with inoperable pancreatic cancer. Br J Cancer (2002) 86(5):680-5. doi: 10.1038/sj.bjc. 6600162

192. Barreto SG, Ramadwar MR, Shukla PJ, Shrikhande SV. Vitamin D3 in operable periampullary and pancreatic cancer: perioperative outcomes in a pilot study assessing safety. Pancreas (2008) 36(3):315-7. doi: 10.1097/ MPA.0b013e31815ac573

193. Blanke CD, Beer TM, Todd K, Mori M, Stone M, Lopez C. Phase II study of calcitriol-enhanced docetaxel in patients with previously untreated metastatic or locally advanced pancreatic cancer. Invest New Drugs (2009) 27(4):374-8. doi: 10.1007/s10637-008-9184-6

194. Borazanci EH, Jameson G, Korn RL, Caldwell L, Ansaldo K, Hendrickson K, et al. A Phase II pilot trial of nivolumab $(\mathrm{N})$ plus albumin bound paclitaxel (AP) plus paricalcitol (P) plus cisplatin (C) plus gemcitabine (G) (NAPPCG) in patients with previously untreated metastatic pancreatic ductal adenocarcinoma (PDAC). Proceedings of the American Association for Cancer Research Annual Meeting 2019; 2019 Mar 29-Apr 3; Atlanta, GA. Philadelphia (PA): AACR; Cancer Res (2019) 79(13 Suppl):Abstract nr CT152. doi: 10.1158/1538-7445.Am2019-ct152

195. Hingorani SR, Zheng L, Bullock AJ, Seery TE, Harris WP, Sigal DS, et al. HALO 202: Randomized Phase II Study of PEGPH20 Plus Nab-Paclitaxel/ Gemcitabine Versus Nab-Paclitaxel/Gemcitabine in Patients With
Untreated, Metastatic Pancreatic Ductal Adenocarcinoma. J Clin Oncol (2018) 36(4):359-66. doi: 10.1200/JCO.2017.74.9564

196. Bailey CJ. Metformin: historical overview. Diabetologia (2017) 60(9):156676. doi: 10.1007/s00125-017-4318-z

197. Algire C, Amrein L, Zakikhani M, Panasci L, Pollak M. Metformin blocks the stimulative effect of a high-energy diet on colon carcinoma growth in vivo and is associated with reduced expression of fatty acid synthase. Endocr Relat Cancer (2010) 17(2):351-60. doi: 10.1677/ERC-09-0252

198. Gou S, Cui P, Li X, Shi P, Liu T, Wang C. Low concentrations of metformin selectively inhibit CD133(+) cell proliferation in pancreatic cancer and have anticancer action. PloS One (2013) 8(5):e63969. doi: 10.1371/ journal.pone.0063969

199. Chae YK, Arya A, Malecek MK, Shin DS, Carneiro B, Chandra S, et al. Repurposing metformin for cancer treatment: current clinical studies. Oncotarget (2016) 7(26):40767-80. doi: 10.18632/oncotarget.8194

200. Duan W, Chen K, Jiang Z, Chen X, Sun L, Li J, et al. Desmoplasia suppression by metformin-mediated AMPK activation inhibits pancreatic cancer progression. Cancer Lett (2017) 385:225-33. doi: 10.1016/j.canlet.2016.10.019

201. Qian W, Li J, Chen K, Jiang Z, Cheng L, Zhou C, et al. Metformin suppresses tumor angiogenesis and enhances the chemosensitivity of gemcitabine in a genetically engineered mouse model of pancreatic cancer. Life Sci (2018) 208:253-61. doi: 10.1016/j.lfs.2018.07.046

202. Kota J, Hancock J, Kwon J, Korc M. Pancreatic cancer: Stroma and its current and emerging targeted therapies. Cancer Lett (2017) 391:38-49. doi: 10.1016/ j.canlet.2016.12.035

203. Kozono S, Ohuchida K, Eguchi D, Ikenaga N, Fujiwara K, Cui L, et al. Pirfenidone inhibits pancreatic cancer desmoplasia by regulating stellate cells. Cancer Res (2013) 73(7):2345-56. doi: 10.1158/0008-5472.CAN-12-3180

204. Mroczko B, Szmitkowski M, Wereszczynska-Siemiatkowska U, Jurkowska G. Stem cell factor and macrophage-colony stimulating factor in patients with pancreatic cancer. Clin Chem Lab Med (2004) 42(3):256-60. doi: 10.1515/ CCLM.2004.047

205. Vasiliades G, Kopanakis N, Vasiloglou M, Zografos G, Margaris H, Masselou $\mathrm{K}$, et al. Role of the hematopoietic cytokines SCF, IL-3, GM-CSF and M-CSF in the diagnosis of pancreatic and ampullary cancer. Int $J$ Biol Markers (2012) 27(3):e186-94. doi: 10.5301/JBM.2012.9348

206. Kuninty PR, Schnittert J, Storm G, Prakash J. MicroRNA Targeting to Modulate Tumor Microenvironment. Front Oncol (2016) 6:3. doi: 10.3389/ fonc. 2016.00003

207. Kwon JJ, Nabinger SC, Vega Z, Sahu SS, Alluri RK, Abdul-Sater Z, et al. Pathophysiological role of microRNA-29 in pancreatic cancer stroma. Sci Rep (2015) 5:11450. doi: 10.1038/srep11450

208. Asama H, Suzuki R, Hikichi T, Takagi T, Masamune A, Ohira H. MicroRNA let$7 \mathrm{~d}$ targets thrombospondin- 1 and inhibits the activation of human pancreatic stellate cells. Pancreatology (2019) 19(1):196-203. doi: 10.1016/j.pan.2018.10.012

209. Chakra Turaga R, Sharma M, Mishra F, Krasinskas A, Yuan Y, Yang JJ, et al. Modulation of Cancer-Associated Fibrotic Stroma by An Integrin alphavbeta3 Targeting Protein for Pancreatic Cancer Treatment. Cell Mol Gastroenterol Hepatol (2020) 11(1):161-79. doi: 10.1016/j.jcmgh.2020.08.004

210. Al Alawi R, Alhamdani MSS, Hoheisel JD, Baqi Y. Antifibrotic and tumor microenvironment modulating effect of date palm fruit (Phoenix dactylifera L.) extracts in pancreatic cancer. BioMed Pharmacother (2020) 121:109522. doi: 10.1016/j.biopha.2019.109522

211. Boj SF, Hwang CI, Baker LA, Chio II, D.D. Engle V, Corbo V, et al. Organoid models of human and mouse ductal pancreatic cancer. Cell (2015) 160(12):324-38. doi: 10.1016/j.cell.2014.12.021

Conflict of Interest: The authors declare that the research was conducted in the absence of any commercial or financial relationships that could be construed as a potential conflict of interest.

Copyright (๐ 2021 Wu, Zhang, Jiang, Werner, Bazhin and D'Haese. This is an open-access article distributed under the terms of the Creative Commons Attribution License (CC BY). The use, distribution or reproduction in other forums is permitted, provided the original author(s) and the copyright owner(s) are credited and that the original publication in this journal is cited, in accordance with accepted academic practice. No use, distribution or reproduction is permitted which does not comply with these terms. 